XI.

\title{
Jahresbericht über die Thätigkeit der Kgl. Universitäts-Ohrenklinik zu Halle a. S. vom 1. April 1891 bis 31. März 1892.
}

\author{
Von \\ Dr. Grunert, \\ I. Assistenzazt der Klinik, \\ und \\ Dr. Panse, \\ Ohrenarzt in Drosden (früherem 1. Assistenzarzt der Klinik).
}

Im Berichtsjahre $1891 / 92$ wurden in der Kgl. UniversitätsOhrenklinik zu Halle a. S. 1662 Patienten behandelt, wobei die aus dem vorigen Berichtsjahre verbliebenen nicht eingeschlossen sind.

In der stationären Klinik wurden 18 Kranke und zwar 12 männliche und 6 weibliche aus dem Vorjahre ïbernommen; neu aufgenommen wurden 167 Kranke, davon 114 männliche und 53 weibliche, so dass im Ganzen 185 verpflegt wurden, 126 männliche und 59 weibliche. Von diesen 185 Kranken wurden 157 entlassen, 106 männliche und 51 weibliche, es verstarben 6 (männliche), so dass am 31. März 1892 noch ein Bestand blieb von 22 Kranken, woron 14 männliche und 8 weibliche.

Auf die 185 stationär behandelten Kranken kommen 7797 Verpflegungstage, auf einen Kranken danach durchschnittlich 42 Tage. Der tägliche durchschnittliche Krankenbestand betrug 19,8. Die höchsten Aufnahmezahlen in die stationäre Klinik betrugen am 17. November und 22. December 18914 Kranke. Der höchste Krankenbestand überhaupt betrug am 17. November 1891 und am 16. und 25. März 189226 Personen, der niedrigste Bestand am 14. Juni 189115 Personen.

Bei der geringen Bettenanzahl (20) konnten bei Weitem nicht alle Gesuche um Aufnahme in die stationäre Klinik Berücksichtigung finden. Es mussten die Betten vorzugsweise für operative Fälle reservirt werden. Nicht operative Fälle wurden, wenn sie von ausserhalb kamen und Aufnahme in die stationäre Klinik nachsuchten, meistens in Privatlogis zu demselben Curkostenpreise 
wie in der stationären Klinik untergebracht und poliklinisch behandelt. Der Mangel an genügendem Platz auf der Station unserer Klinik brachte es auch mit sich, dass operative Fälle vielfach in poliklinische Behandlung entlassen wurden, sobald ihr allgexneiner Gesundheitszustand dies irgend erlaubte. So wurden z. B. Fälle, bei denen die Hammer-Ambossextraction ausgefiburt worden war, oft schon nach 8 Tagen zu poliklinischer Weiterbehandlung entlassen.

Die Zahl der die Klinik besuchenden Studenten betrug nach dem Ausweis der officiellen Quästurlisten : im Sommersemester 1891 für die klinischen Vorlesungen 41, fuir das Publikum 36, im Wintersemester 1891/92 für die Klinik 22, für das Publikum 17. Dazu kamen noch 11 Aerzte, darunter 5 Ausländer. Die Verbältnisse des Alters, der Heimath der Patienten, der Erkrankungen und der Operationen ergeben sich aus den folgenden Tabellen:

I. Alterstabelle.

\begin{tabular}{c|c|c|c}
\hline Al ter & Männlich & Weiblich & Summa \\
\hline $0-2$ Jahre & 63 & 59 & 122 \\
$2-10=$ & 238 & 238 & 476 \\
$11-20=$ & 266 & 181 & 447 \\
$21-30=$ & 152 & 87 & 239 \\
$31-40=$ & 92 & 66 & 158 \\
$41-50=$ & 65 & 32 & 97 \\
$51-60=$ & 43 & 24 & 67 \\
$61-70=$ & 25 & 15 & 40 \\
$71-90=$ & 4 & 4 & 8 \\
$81-90=$ & - & - & 8 \\
Onbekannt & 6 & 2 & 8 \\
\hline
\end{tabular}

I. Meimathstabelle.

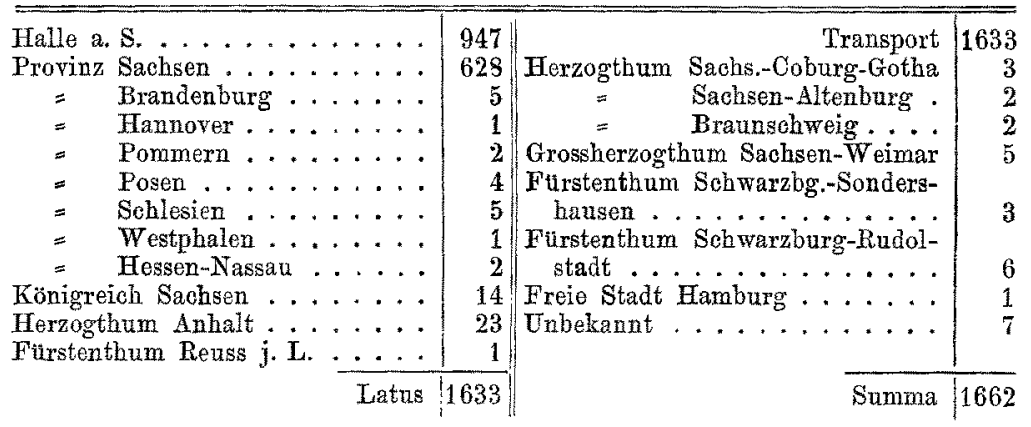


III. Krankheitstabelle.

\begin{tabular}{|c|c|c|c|c|c|c|c|c|}
\hline Nomen morbi & 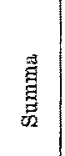 & 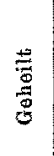 & 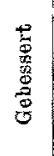 & 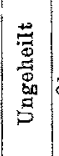 & 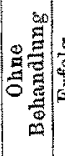 & 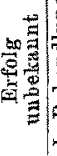 & 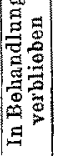 & 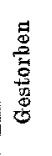 \\
\hline Ohrmuschel. & & & & & & & & \\
\hline Verletzungen $\ldots \ldots \ldots \ldots \ldots$ & 1 & 1 & - & - & - & -1 & - & - \\
\hline Congelatio $\ldots \ldots \ldots \ldots \ldots$ & $i$ & 1 & - & - & - & - & - & - \\
\hline Nenbildangen (Lapus 1, Carcinom 1) . . . & 2 & 2 & - & - & - & - & - & - \\
\hline Othaematom (traumatisch) $\ldots \ldots \ldots$ & 1 & 1 & - & - & - & - & - & - \\
\hline $\begin{array}{l}\text { Erysipel } \ldots \ldots \ldots \\
\text { A } \ldots \text { usserer Gehörgang. }\end{array}$ & 1 & 1 & - & - & - & - & - & - \\
\hline Verletzangen $\ldots \ldots \ldots \ldots \ldots \ldots$ & 2 & 2 & - & - & - & - & - & - \\
\hline Angeborene Deformitäten $\ldots \ldots \ldots$ & 1 & - & - & - & 1 & - & - & - \\
\hline Fremdkörper $\ldots \ldots \ldots \ldots \ldots \ldots$ & 48 & 48 & - & 一 & - & - & 一 & - \\
\hline Vermeintlicher Fremdkörper . . . . . . . & 1 & - & - & - & - & - & - & - \\
\hline Cerumen obturans (einseitig 98, doppelseitig 68) & 166 & 164 & - & 一 & - & 2 & 一 & - \\
\hline 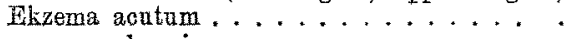 & 36 & 35 & - & - & - & 1 & - & - \\
\hline Otitis externa circumscripta (Furnikel) (acut & 22 & 17 & $\longrightarrow$ & - & - & 5 & - & - \\
\hline 35 , chronisch 1) $\ldots \ldots \ldots \ldots$ & 36 & 36 & - & - & - & -1 & - & - \\
\hline Otitis externa diffusa acuta $\ldots \ldots \ldots$ & 16 & 14 & - & 一 & $一$ & 2 & - & - \\
\hline $\begin{array}{c}=\quad=\text { chronica } \ldots \ldots \ldots \\
\text { Trommelfell. }\end{array}$ & 8 & 6 & - & - & - & 2 & - & - \\
\hline Ruptur (dureh ohrfeige 6 ) $\ldots \ldots \ldots$ & 18 & 16 & - & - & -1 & 2 & $1-$ & - \\
\hline $\begin{array}{c}\text { Myringitis chronica............ } \\
\text { Mittelohr. }\end{array}$ & 1 & 1 & - & - & - & -1 & $1-$ & - \\
\hline $\begin{array}{l}\text { Acuter seröser Katarrh (einseitig } 79 \text {, doppel- } \\
\text { seitig } 33 \text { ) } \ldots \ldots \ldots \ldots \ldots \ldots \\
\text { Acuter sohleimiger Katarrh }\end{array}$ & 112 & 95 & 2 & - & - & 15 & $1-$ & - \\
\hline $\begin{array}{l}\text { Subacuter Katarrh (einseitig } 34 \text {, doppels. } 10 \text { ) } \\
\text { Chronischer Katarrh der Paukenhoble (ein- } \\
\text { seitig 138, doppelseitig } 232 \text {; mit Exsudat } 23 \text {, } \\
\text { mit Tubenstenose 97, mit Sklerose 37) . }\end{array}$ & 44 & 39 & 1 & $1-$ & - & 4 & $1-$ & - \\
\hline 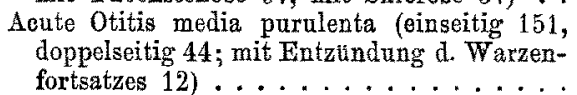 & 195 & 00 & $+x$ & - & $\$ 1$ & $100]$ & $1=$ & - \\
\hline $\begin{array}{l}\text { Subacute Otitis media puralenta (einseitig } 7 \text {, } \\
\text { doppelseitig } 4) \ldots \ldots \ldots \ldots \ldots \ldots\end{array}$ & 11 & 114 & 1 & - & - & & - & - \\
\hline $\begin{array}{l}\text { Chronisohe otitis media purulenta (einseitig } \\
278 \text {, doppelseitig } 59 \text {; mit Caries 44, mit } \\
\text { Polypen 41, mit Cholesteatom 15, mit Ent- }\end{array}$ & & & & & & & & \\
\hline $\begin{array}{l}\text { zundung des Warzenfortsatzes } 10) \ldots \ldots \\
\text { Residuen chronischer Eiterungen } \ldots \ldots\end{array}$ & $\begin{array}{l}367 \\
108\end{array}$ & 173 & $\underline{5}$ & 14 & $\begin{array}{r}10 \\
108\end{array} \mid$ & 161 & 4 & - \\
\hline $\begin{array}{l}\text { Nenralgia plexus tympanici (aus Angina } 1 \text {, } \\
\text { Zahncaries } 56 \text {, Anämie } 2 \text {, Syphilis } 1 \text {, unbe- }\end{array}$ & & - & & & & & 一 & \\
\hline $\begin{array}{c}\text { kannter Ursaehe } 13 \ldots \ldots \ldots \\
\text { Inneres ohr. }\end{array}$ & 75 & 53 & - & - & 1 & 21 & - & - \\
\hline $\begin{array}{l}\text { Acute Nerventaubheit durch Labyrintherkran- } \\
\text { knng (Commotion 2, Infuenza 1) . . } \\
\text { Chronische Nerventaubheit duroh Labyrinth- } \\
\text { affection (einseitig 16, doppelseitig 12; Sy- } \\
\text { philis 1, Toterus 1, Intoxieation 1, Tabes 1, } \\
\text { ex professione 1).............. }\end{array}$ & 28 & - & - & 2 & 25 & 1 & - & - \\
\hline
\end{tabular}




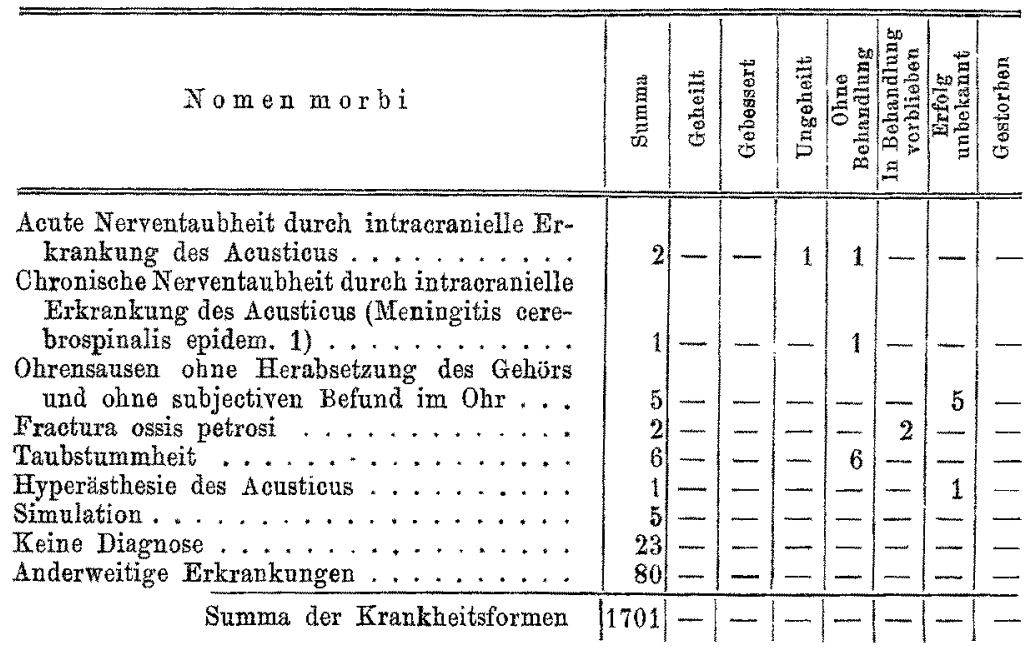

IV. Operationstabelle.

\begin{tabular}{|c|c|c|c|c|c|c|c|c|}
\hline Nomen operationis & 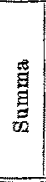 & 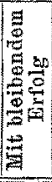 & 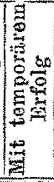 & 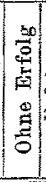 & 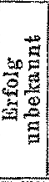 & 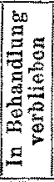 & 总 & 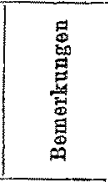 \\
\hline Operationen an der Ohrmusehel....... & $1)$ & 1 & - & - & - & - & - & - \\
\hline 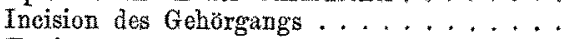 & 18 & 18 & - & - & - & -. & -1 & - \\
\hline Entfernung ron Fremdkörpern (durch Injeo- & & & & & & & & \\
\hline tion 39 , instrumentell $9, \ldots \ldots$ & 48 & 48 & - & - & - & - & - & - \\
\hline Polypenextraction $\ldots \ldots \ldots \ldots \ldots \ldots$ & 64 & - & - & - & - & - & -1 & - \\
\hline Paracentese $\ldots \ldots \ldots \ldots$ & 41 & 41 & - & - & 一 & - & - & - \\
\hline Operative Eröffnung des Antrum ...... & 85 & 52 & - & 22 & 5 & 2 & 4 & - \\
\hline Tenotomie des Tensor tympani $\ldots \ldots \ldots$ & 1 & - & 1 & - & - & - & - & - \\
\hline Hammerexcision $\ldots \ldots \ldots$ & 9 & 5 & - & 4] & - & - & - & $\begin{array}{l}2 \text { mal der } \\
\text { Stapes } \\
\text { mit ent } \\
\text { fernt }\end{array}$ \\
\hline Hammer-Ambossextraction & 17 & 8 & - & 9 & - & - & - & - \\
\hline Adenoide Vegetationen $\ldots \ldots \ldots \ldots$ & 61 & 61 & - & - & - & - & - & - \\
\hline Nasenpolypen $\ldots \ldots \ldots \ldots \ldots \ldots$ & 29 & - & - & - & - & - & - & - \\
\hline $\begin{array}{l}\text { Exstirpation ron Geschwulsten in der Um- } \\
\text { gebung des ohres und Eroffnung ron Sen- } \\
\text { kungsabscessen } \ldots \ldots \ldots \ldots \ldots\end{array}$ & 6 & 6 & - & - & $\ldots$ & - & - & - \\
\hline 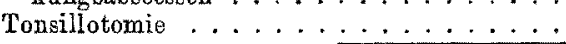 & 84 & - & 一 & - & - & - & - & - \\
\hline Summa & 24 & - & 一 & - & - & - & & \\
\hline
\end{tabular}

Die Hammerexcision vom Gehörgange aus wurde in dem Berichtsjahre $26 \mathrm{mal}$ vorgenommen, 9 mal wurde zugleieh mit dem Hammer der Amboss entfernt. In allen Fällen war die Indication zur Operation auf Grund des Bestehens hochgelegener Perforationen gestellt, nie wurde in diesem Berichtsjabre zur Operation 
geschritten, um bei chronischem sklerosirenden Katarrh eine Hörverbesserung durch dieselbe zu erzielen. Die im 33. Bd. d. A. S. $207^{\text {l) }}$ u. f. aus unserer Klinik publicirten diagnostisehen Anhaltspunkte für das Bestehen einer Ambosscaries baben sich anch weiterhin als praktisch wichtig bestätigt. Das Ergebniss der Operation war folgendes: unter 9 Hammerexcisionen wurden 5 mit bisher bleibendem Erfolg geheilt, unter 17 Hammer-Ambossextractionen 8, ein Resultat, welches ungefähr übereinstimmt mit den friberen aus unserer Klinik publicirten Erfahrungen, welche auf einem dreimal so grossen Beobachtungsmaterial basiren. In zwei Fällen wurde zugleich mit dem Hammer der Stapes extrahirt, ohne dass sich irgend welche Erscheinungen von Schwindel zeigten (in dem einen Falle - Ida Elbe - sass das kranke Kind etwa 4 Stunden nach der Operation, mit Spielzeng beschäftigt, aufrecht im Bett). Andere infauste Erseheinungen blieben bei der unbeabsichtigten Stapesextraction ebenfalls aus.

Die Ursache davon, dass nur etwa die Hälfte der Fälle, in denen die Hammer-Ambossextraction ansgeführt wurde, zur Heilung kamen, ist darin zu suchen, dass häufig die Caries der beiden äusseren Gehörknöchelchen complicirt ist mit anderweitig localisirter Caries, insbesondere des Antrum mastoideum, ohne dass sichere hierauf hindentende diagnostische Anhaltspunkte vorhanden sind. In diesen Fällen haben wir in der Reichhaltigkeit der Secretion ein einziges Moment, welches uns die Vermuthung nahe legen kann, dass die Caries nicht auf die beiden äusseren Gehörknöchelchen beschränkt ist, selbst wenn der otoskopische Befund für eine isolirte Caries derselben zu sprechen scheint.

Im Uebrigen ist selbst dann, wenn die Gehörknöchelchenextraction nicht zur Heilung der chronischen Otorrhoe führt, den Kranken dadurch genützt, dass durch den Eingriff der für den Eintritt von Eiterretention so sehr disponirte Atticus tympanicus freigelegt ist. Der Eiter hat nun besseren Abfluss, der häufig bestehende halbseitige chronische Kopfschmerz verliert sich, und die Gefahr, dass ein Durchbruch der Eiterung in das Schädelinnere durch das Tegmen tympani - erfahrungsgemäss die häufigste Durchbruchsstelle - stattfindet, ist, wenn nicht beseitigt, so doch auf ein Minimum reducirt (prophylaktischer Werth der HammerAmbossextraction). Wir haben auch die Beobachtung gemacht,

1) Grunert, Weitere Mittheilungen über die Hammer-Ambossextraction mit besonderer Rucksicht auf die Diagnose der Ambosscaries. 
dass in Fallen, in denen, weil die Hammer-Ambossextraction nicht zur Ausheilung der chronischen Otorrhoe ausgereicht hatte, nach Jahr und Tag zur Aufmeisselung des Antrum mastoideum geschritten wurde, nach diesem Eingriff die Heilung dann auffallend schnell erfolgte. Das doch immerhin häufige Misslingen der Ambossextraction nach der Excision des Hammers lässt die jetzige Technik der Ambossextraction als eine noch unvollkommene erscheinen. Als Grund dieses Misslingens haben wir öfters den Umstand kennen lernen, dass in dem Moment, in welehem mit der Wilde'schen Schlinge der Hammerkopf aus dem Atticusraum herausgehebelt wurde, der Amboss dislocirt wurde und auf den Boden der Paukenhöhle fiel. Mit dem Auge vermag man diesen Vorgang nicht zu verfolgen, weil in dem bezeichneten Momente die gewöhnlich sehr profus werdende Blutung in der Tiefe das Gesichtsfeld verdunkelt. Ist der Amboss auf den Boden gefallen, so kann er sehr leicht, besonders wenn er nur noch rudimentär ist, in die Klüftungen des Paukenhöhlenbodens eingekeilt werden. Misslingt es, den Amboss vom Gehörgange aus zn entfernen, so haben wir als letztes Refugium noch das Stacke'sche Verfahren der Gehörknöchelchenextraction, welches, wenn man die Technik beherrscht, stets zum Ziele führen muss.

Das häufige Misslingen der Ambossextraction vom Gehörgange aus veranlasste uns zu Versuchen an der Leiche, den Amboss vor dem Hammer zu extrahiren. Wir gingen dabei von dem Gedanken aus, dass der Hammer viel weniger leicht dislocirt werden kann, als der Amboss, weil er durch die Sehne des M. tensor tympani festgehalten wird. So selr uns diese Leichenversuche befriedigt haben, so haben wir ihre praktische Verwerthbarkeit bisher noeh nicht am Lebenden erprobt.

In einem Falle (Dorette Witthöft) wurde wegen permanenten Ohrensausens, welches nach Influenza zurückgeblieben war, die Tenotomie des M. tensor tympani ausgefubrt, allerdings nur mit temporärem Erfolge für die Dauer eines Monats. Länger hielt auch nicht die geringe durch den Eingriff erzielte Hörverbesserung von $6 \mathrm{zu} 10 \mathrm{Cm}$. für Flüsterzahlen an.

Die Mastoidoperation wurde in den acuten Fällen mit demselben Erfolge wie früher in der bewährten früheren Weise ausgeführt. Die $\mathrm{chr}$ o $\mathrm{n}$ is $\mathrm{ch}$ en Fälle wurden sämmtlich nach Stacke's Verfahren mit einigen Modificationen, deren Zweckmässigkeit sich herausstellte, operirt. Die Ergebnisse der Mastoidoperation ersehen wir aus der zum Schluss beigefugten Tabelle; 
die näheren Mittheilungen darüber sind aus unserer Klinik publicirt worden.

Die Operationen adenoider Vegetationen im Nasenrachenraum wurden, wie tuberhaupt in den letaten Jahren, zum grössten Theil mit dem scharfen Löffel ohne Narkose ausgeführt. Nach abgelanfener Nachbehandlung besteht häufig infolge der langen Gewöhnung das Mundathmen noch fort, ohne dass ein Hinderniss für die Nasenathmung noch vorhanden ist. Da hat die Erziehung einzusetzen; die Kinder müssen immer wieder darauf aufmerksam gemacht werden, dass sie mit geschlossenem Munde athmen sollen. Diese erziehliche Beeinflussung Seitens der Angehörigen ist in manchen Fällen ebenso nothwendig, als der Versuch, vor Beseitigung des Athmungshindernisses dureh Erziehungsmittel das Mundathmen zu bekämpfen, erfolglos und grausam ist. Entzündungen des Mittelohres mit Ausgang in Eiterung haben wir nur zweimal in den 61 Fällen der Löffeloperation folgen sehen, dagegen häufig den resorptionsbegünstigenden Einfluss auf chronische Exsudate resp. Transsudate der Pankenhöhle constatiren. können. Nur in relativ seltenen Fällen war es nöthig, die Paracentese zur Exsudatentleerung der Löffeloperation folgen zu lassen.

Die Erfahrungen über die Influenza-Otitiden, welche wir im letzten Vierteljahre des Berichtsjahres zu beobachten Gelegenheit hatten, sind von Herrn Dallwig in einer Inauguraldissertation veröffentlicht worden. Erwähnt sei nur an dieser Stelle, dass wir im Gegensatz zu der Influenza-Epidemie $1889 / 90^{\prime}$ ) relativ häufig hämorrhagische Extravasate im Trommelfell beobachtet haben.

Was die Zuverlässigkeit der Zahlenangaben über die kleineren chirurgischen Eingriffe (Paracentesen, Polypenoperationen u.s.w.) anbetrifft, so kann auf das hieriber im vorigen Jahresbericht Gesagte verwiesen werden. ${ }^{2}$ )

Es folgen zunächst die Krankengeschichten der letal verlaufenen Fälle, und zwar sind dies im Berichtsjahre 6 .

1. Alfred Schmoll, 8 Jahre alt, Vater Maurer in Halle a. S. Rec. 30. April 1891. Meningitis tuberculosa. Der Kranke ist im Jahre 1889 rom 28. Juli bis 4. September wegen acuter rechtsseitiger Mittelohreiterung mit Empyem des Warzenfortsatzes in stationärer Behandlung unserer Klinik gewesen. Die Otitis des bis dahin vollkommen gesunden rechten Ohres soll damals durch Uebergiessung des Kopfes mit kaltem Wasser entstanden sein.

1) Ludewig, Influenza-Otitis. Archif f. Ohrenheilkunde. Bd. XXX. S. 204 u.f.

2) Ebenda. Bd. XXXIII. S. 41. 
Bei der Aufmeisselung wurde damals pus bonum et laudabile ans dem Warzenfortsatz entleert, der Knabe nach ca. 6 Wochen mit fester Narbe geheilt entlassen. Am Ohr ist seit jener Zeit von den Angehörigen njchts Abnormes wieder bemerkt worden. Wohl aber hat er hăufig uber excessive Kopfschmerzen geklagt, welche er immer auf den Scheitel localisirt hat. In der Nacht ist den Eltern häufig plötzliches Aufschreien in Schlafe aufgefallen. Des Morgens beim Aufstehen oft Schwindel von minutenlanger Dauer, der ihn oft gezwungen hat, sich wieder zu Bett zu legen. Er ist stets sehr elend gewesen und hat stets Neigung zu Obstipation gezeigt. 14 Tage vor seiner Aufnahme in die Klinik hat sich dieser Zustand wesentlich verschlimmert. Der Schwindel wurde so anhaltend, dass er das Bett nicht mehr verlassen konnte. Zugleich heftiges Erbrechen nach jeder Mahlzeit, spontan nie. Zugleich Klage über die heftigsten Kopfschmerzen im Scheitel und Hinterhaupt und heftige Schmerzen im Genick, welches 2 Tage lang ganz starr gewesen sein soll. Allabendlich starke Hitze ohne Schättelfröste, häufig Delirien und Bewusstlosigkeit, lautes Stöhnen. Anch soll 3 Tage lang eine starke Contractur im rechten Ellbogengelenk und in den Fingergelenken der rechten Hand bestanden haben, die Faust sei krampfhaft geschlossen gewesen. Dieser Contracturzustand soll mit der eintretenden Genickstarre begomen und mit dem Aufhören der Genickstarre nach 2 Tagen sich wieder verloren haben. In den letzten 8 Tagen vor seiner Aufnahme bemerkte die Mutter "Schiefstellung des rechten Auges", und der Kranke gab seit der Zeit in den delirienfreien Intervallen an, dass er doppelt săhe.

Status praes. vom 30. April 1891 Nachmittags 5 Uhr: Sehr blasser anämischer Knabe; die Gesichtsfarbe hat einen Schein ins Gelbe. Apathisch, aber vollkommen freies Sensorium. Auf Befragen, was ihn schmerze, antwortet er: ,mein Kopf". Puls gut und kräftig, aber etwas arhythmisch; bei einer Temperatur von $38^{\circ}$ hat er eine Pulsfrequenz ron 69 . Strabismus convergens. Das Yorhandensein von Doppelbildern konnte nicht sicher constatirt werden, wobl aber griff er, anfgefordert, das Stethoskop zu fassen, wiederholt fehl und machte den Eindruck, als sähe er dasselbe doppelt, was er indess in Abrede stellte. Zunge roth, nicht belegt, zeigt fibrilläre Znckungen. Keine Motilitäts- und Sensibilitätsstörungen. Die Kopfhaut ist byperästhetisch; Percussion des ganzen Schädels schmerzhaft, besonders nach dem Hinterhaupte hin. Während er im Bett liegt, keỉn Schwindelgefühl, sobald er sich aufrichtet, „wird es ihm schwarz vor den Augen", ebenfalls kann er wegen sich einstellenden starken Schwindels weder stehen, noch gehen.

Die inneren Organe lassen krankhafte Veränderungen nicht erkennen. Stuhl angehalten, Urin eiweissfrei.

Ophthalmoskopischer Befund (Dr. Braunsehweig): Mit Sicherheit keine Neuritis optica, rechts etwas Venenektasie.

In der Umgebung beider Ohren keine entzündlichen Erscheinungen, hinter dem rechten $\mathrm{Ohr}$ die alte vollständig reactionslose Operationsnarbe. Der rechte Gehörgang normal weit, das Trommelfell blass, in seiner hinteren Hälfte eine Jängliche Narbe. Das linke Trommelfell ist getrübt und mässig eingezogen. Flüsterzahlen beiderseits sicher $1_{1 / 2}$ Meter. Hohe Töne beiderseits deutlich, $\mathrm{C}_{1}$ vom Scheitel scheint uach rechts etwas verstärkt zu sein.

Ordination: Essiglarement, Eisblase auf den Kopf.

2. Mai. Nach dem Lavement ist reichliche Defäcation erfolgt. Zustand 
unverändert. Hauptklage: heftige Kopfsehmerzen. 1 Uhr Mittags: bei einer Temperatur von $39^{\circ}$ ein Puls von 122. Sensorium frei, keine Motilitäts- und Sensibilitiatsstörungen.

3. Mai. Sehr somnolent; hat gestern wässerige Flüssigkeit erbrochen.

5. Mai. Gestern Mittag Erbrechen vor dem Mittagessen. Sehr apathisch und somnolent.

8. Mai. Gestern Abend von 9 bis $3 / 410$ Uhr nach vorangegangenem heftigen Erbrechen Opisthotonus und klonische Krämpfe der oberen und unteren Extremitäten; lăngere Zeit tonische Contractur im rechten Ellbogengelenk und den Fingergelenken der rechten Hand. Augen dabei nach oben verdreht, völlige Bewusstlosigkeit. Heute Morgen das Sensorium nicht ganz frei, nur auf lautes Anrufen reagirt er.

9. Mai. Gestern Nachmittag wieder Spontanerbrechen; Singultus. Sehr somnolent.

10. Mai. Pupillen maximal weit, reflectorische Starre derselben; ophthalmoskopische Untersuchung abermals von negativem Ergebniss. Keine Motilitätsstörungen; schluckt noch reflectorisch bei vollkommen benommenem Sensorium. Milzdämpfung scheint vergrössert.

11. Mai. Lässt Urin und Faeces unter sicb, im Uebrigen St. idem.

12. Mai. Rasselgeräusche über der ganzen vorderen Thoraxseite. CheyneStokes'sches Athmen. Allgemeine Parese der Motilität und Sensibilität. Fuliginöser Belag der cyanotischen Lippen. Des Morgens um 7 Uhr Temperatursteigerung auf 40,5. Permanentes Thränenlaufen. Nachmittags 5 Uhr Exitus letalis im Coma.

Temperaturverlauf: Das Fieber bewegte sich in mässigen Höhen, es überschritt kaum 39. Erst in den letzten 3 Tagen vor dem Tode ging es successive in höhere Grade über; am Morgen des Todestages trat eine prämortale Steigerung bis auf $40,5^{\circ}$ ein.

Autopsie: Hirnoberflache sehr trocken; Venen stark injicirt; Gyri stark abgeflacht. An der Convexität beiderseits in einzelnen Gefässmaschen gelbliche Exsudatflecke. An der Basis in der Umgebung der Vierhügel sulziges, gelbliches Exsudat. Einzelne miliare Knötchen in der Pia, dem Verlauf der Gefässe enteprechend. Hydrocephalus internus, Erweichung des Corpus callosum.

An den Lungen, ausser einer strahligen Narbe in der Pleura der linken Spitze und einigen angeschwollenen Bronchialdrüsen, nichts Abnormes. Milz, Leber und Nieren waren vergrössert und blutreich; einige Mesenterialdrïsen zeigten sich vergrössert und im Mesenterium ein vereinzeltes verkalktes Drüsenpacket.

Epikrise: In diesem Falle ist der Tod an Meningitis tuberculosa erfolgt. Die Infection der Meningen ist wohl zweifellos in Zusammenhang zu bringen mit den bei der Autopsie gefundenen Sehwellungen der Bronchial- oder Mesenterialdrüsen. Einen direeten Zusammenhang der tuberculösen Meningitis mit dem $13 / 4$ Jahre vorher mit Erfolg behandelten Leiden des rechten Ohres anzunebmen, liegt um so weniger eine Veranlassung vor, als die Section des der Leiche entnommenen rechten Schläfen- 
beins eine vollständige Ausheilung des früheren Leidens erwies. Das Trommelfell war blass, die alte Perforation vernarbt, die Paukenschleimhant war von normaler Zartheit und Transparenz, im Antrum mastoideum zeigte sich keine Spur von Eiterung. Die alte Meisseloffnung in der Corticalis war durch Neubildung von Corticalis bis auf die Grösse etwa eines Linsenquadranten reducirt worden.

2. Albert Mehlis, 10 Jahre alt, Vater Handarbeiter in Osendorf bei Halle. Rec, 5. Juni 1891. Das linke $\mathrm{Ohr}$ soll früher hin und wieder gelaufen haben, andere Beschwerden seitens des Ohres hat er indess nicht gehabt. Vor 3 Wochen plötzlich die heftigsten Schmerzen links, die einige Tage anhielten und mit Eintritt einer profuseren Eiterung aus dem $0 \mathrm{hr}$ geringer wurden. 8 Tage vor seiner Aufnahme in die Klinik wurde ein secundärer Furunkel der hinteren Gehörgangswand in der Poliklinil incidirt. Seit 4 Tagen vor seiner Aufnahme starke Exacerbation der Schmerzen im linken Ohr. Dazu gesellten sich Spontan- und Druckschmerz vor und hinter dem kranken Ohr und quălende Kopfschmerzen der ganzen linken Kopfhälfte. Allabendlich starke Hitze, aber kein Schüttelfrost. Im Laufe des Aufnahmetages 3 maliges Erbrechen, spontan und nach dem Essen, und Temperatursteigerung bis über $40^{\circ}$ ohne vorhergegangenen Schüttelfrost. Erscheinungen von Schwindel, sowie Couvulsionen sind draussen nicht beobachtet. Obstipation seit 3 Tagen.

Status praesens: Krăftiger, gut genährter Junge. 7 Uhr Abends: Puls 120, Respiration 32, Temperatur 40,10. Brust- und Bauchorgane zeigen keiue krankhaften Veränderungen.

Taumelt beim Stehen und Gehen mit offenen, stärker mit geschlossenen Augen; eine besondere Richtung beim Taumeln ist nicht ausgesprochen. Keine Motilităts - und Sensibilitătsstörungen. Pupillen sind gleich weit und reagiren gut auf Lichteinfall. Zunge belegt, nicht sehr trocken. Links: Infiltration und Druckschmerz vor dem $\mathrm{Ohr}$, hinter dem Ohr keine Infiltration oder Oedem, wohl aber Schmerz bei der leisesten Berührung auf dem ganzen Processus mastoideus, am stäarksten nach der Spitze zu. Starker Druckschmerz und Infiltration in der Jugularisgegend. Der linke Gehörgang zeigt spaltförmige Stenose durch Senkung der hinteren oberen häntigen Gehörgangswand. Fötide Otorrhoe. Rechts: Diffuse Trübung des Trommelfells. Flüsterzahlen: links nicht einmal durch Hörschlauch, rechts $1 \frac{1 / 2}{2}$ bis 2 Meter, Fis auf der linken Seite stark herabgesetzt. $C_{1}$ rom Scheitel inconstant, wird härtiger nach der gesunden rechten Seite verstärkt angegeben. Beim Cath. tubae zeigt sich links deutliches Perforationsgeräusch mit Rasseln.

Ordination: Eisbeutel hinter das Ohr, Lavement, Sublimatausspülungen $(1,0: 10,000)$ des Ohres.

6. Juni. Morgentemperatur $40,1^{\circ}$. Im Gehörgange steht bis zum Eingange desselben eine dunkelbraune, dünnflüssige, sehr fötide Flüssigkeit. 0,3 Calomel.

7. Juni. Gestern Abend Temperaturabfall bis $38,8^{\circ}$. Druckschmerz geringer. In der Nacht starke Delirien; Keine Zeichen von Meningitis. Ophthalmoskopischer Befund negativ (Dr. Braunschweig).

8. Juni. In vergangener Nacht viel delirirt. Morgentemperatur $39,3^{\circ}$. 
Aufmeisselung links: Die Knochenoberfläche zeigt, abgesehen von erweiterten Gefässlöcheren, nichts Abnormes; beim Vorschieben des Periostes quilt dünnflüssiger, jauchiger Eiter zwischen häutiger und knöcherner hinterer Gehörgangswand hervor. Bei den ersten Meisselschlägen in die Corticalis pulsirt lebhaft Eiter von gleicher Beschaftenheit hervor. Der ganze Warzenfortsatz, welcher sehr reichliche pneumatische Hohläume zeigte, war rom Antrum mast. bis zur Spitze erfüllt von jenem jauchigen Eiter. Die Spitze wurde vollkommen entfernt. Die hintere Wandung der Knochenhöhle ist schwärzlich verfärbt. Bei Fortnahme der verfärbten Knochenpartien wird der Sinus transversus in etwa 5 Pfennigstückgrösse blossgelegt; seine Wandung erscheint schmutzig graublau verfärbt. Zwischen Sinuswand und Knochen quillt jauchiger Eiter hervor. Spülwasser nicht durchgängig nach der Paukenhöhle zu; fünf Nähte; Tamponade mit Jodoformgaze. Am Abend des Operationstages $40^{\circ}$ Temperatur; kein schmerzlindernder Effect der Operation.

9. Juni. Morgentemperatur $36,9^{\circ}$. Die Schmerzen bestehen fort. Sensorium zeitweise benommen; er reagirt nur auf stärkeres Anrufen. Klage über Schmerzen im Kopf. Geringe Cyanose der Lippen. Bulbi etwas nach oben verdreht, die Pupillen gleichweit und gut auf Lichteinfall reagirend.

10. Juni. In der Nacht gegen 4 Uhr Morgens hat er wegen starker Kopfschmerzen heftig geschrieen. Norgens $3 / 48 \mathrm{Uhr}$ Sensorium benommen; Bulbi nach oben verdreht, Pupillen maximal weit, reagiren nicht auf Lichteinfall. Beide Arme hängen schlafi herunter, die Beine zeigen noch einen gewissen Tonus. Allgemeine Hyperästhesie, sicher keine Spur von Sensibilitätsparese. Stertoröses Athmen; seit $9 \mathrm{Uhr}$ dentliche Zeichen des Eintrittes von Lungenödem. In diesem Zustande Exitus letalis gegen 1 Uhr.

Ergebniss der Autopsie: Im linken Sinus transversus findet sich eine erweichte, grüngelblich aussehende, der Wand fest anhaftende Thrombenmasse.

Eitriger Belag an der Basis des Kleinhirns. Die Pia ist sehr blutreich. Die Arterien der Basis sind leicht mit Blat gefült. In den Seitenventrikeln finden sich geringe Mengen heller Flüssigkeit. Weisse Substanz feucht, glänzend; lasst auf dem Durchschnitt eine reichliche Menge Blutpmite erkennen. Kleinhirn und Grosshirn blutreich.

Abdominalorgane: Blase starls ausgedehnt; in der Bauchbohle eine mässige Menge gelber Flüssigkeit. Milz sehr weich, Zeichnung auf dem Durchschnitt versehwommen. Drusen des Mesenteriums leicht geschwollen. Leber sehr fest, von mässigem Blutgehalte; periphere Fettinfiltration. Nieren ohne pathologische Veränderungen.

Brustorgane: Rechte Lunge durch alte strangförmige Adhäsionen mit der Brustwand verwachsen. Die Pleuraoberfläche der linken Lunge zeigt am Jateralen Rande schwarze subpleurale Blutergüsse (Y-Form). Beide Lungen sind sehr blutreich, aber uberall lufthaltig. Anf der Pleura des Oberlappens der rechten Lunge zeigt sich eine Anzahl dicht bei einander stehender submiliarer, transparenter Knötchen. In der Nähe derselben, dicht unter der Pleura gelegen, eine etwa bohnengrosse peribronchiale verkäste tuberculöse Masse.

Herz normal.

Section des linken Schläfenheins: In der gesenkten hinteren oberen häutigen Gehörgangswand sieht man die Incisionsstelle (vermeintlicher FurunArchiv f. Ohrenheilhunde. $\mathrm{XXXV}, \mathrm{Bd}$. 
kel). Der Durchbruch in der knöchernen hinteren Gehörgangswand ist in seiner Umgrenzung nicht mehr zu sehen, weil die Wand bis zur Durehbruchsstelle bei der Operation fortgenommen worden ist. Das Trommelfell ist abgeffacht und zeigt eine fast centrale, stecknadelkopfgrosse Perforation. Die Paukenhöhle war angefüllt mit eingedicktem Eiter; eine etwa linsengrosse blassrothe Granulation verlegt den Aditns ad antrum. Das Hammer-Ambossgelenk war gelöst. An dem Facialis- und Acusticusstamm im Meatus auditor. int. war nichts von Eiter zu sehen; ebenfalls nicht am Aquaeductus vestibuli und Canalis petroso-mastoideus. Eine cariöse Stelle am Dach der Paukenhöhle oder im Sulcus transv. bestand nicht.

Im Anschluss an diesen Fall soll noch einmal hervorgeboben werden, wie leicht es unter Umständen sich ereignen kann, dass man eine Senkung der hinteren oberen Gebörgangswand mit einem Furunkel verwechselt, und zweitens, dass die Ursache der Undurchgängigkeit des Aditus ad antrum für das Spülwasser bei der Section des Schläfenbeins in einer den Aditus verlegenden Granulation gefunden wurde.

3. Franz Hessler, $93 / 4$ Jahre alt, Vater Kossath in Pannigkau. Rec, am 22. Mai 1891. Chronische Eiterung rechts mit Caries und eitriger Sinusphlebitis. Ohreiterung rechts seit Weihnachten 1890 mit acutem Beginn, (Heftiges rechtsseitiges Ohrenreissen, welches mit Beginn der Eiterung nachliess.) Die Ohraffection stellte sich ein in Anschluss an einen starken Schnupfen. Die Eiterung wurde mit der Zeit weniger profus, als im Anfange, hat aber nie ganz aufgehört. Der früher angeblich stets gesunde Knabe kränkelte seit dieser Zeit und wurde wegen "chronischen Magenkatarrhs" ärztlich behandelt. 14 Tage vor seiner Aufnahme in die Klinik von Neuem die heftigsten Schmerzen im rechten $\mathrm{Ohr}$, starke Kopfschmerzen, besonders in der rechten Kopfhälfte, viel Schwindel, einige Male spontanes Erbrechen, hartnäckige Obstipation, ausgesprochene Somnolenz. Krampferseheinungen wurden von den Eltern ebensowenig gesehen wie ausgesprochene Schüttelfröste. In der Familie der Mutter sind wiederholt Todesfälle an Phthisis pulmonum vorgekommen.

Status praes. : Schlechtgenährter Knabe; exquisit phthisischer Habitus, flacher Thorax. Wenig ansgiebige Athmenexcursion desselben, 62 bis $65 \mathrm{~cm}$ in der Höhe der Brustwarze. Die linke Thoraxhälfte ist flacher als die rechte. Deutlich relative Dämpfung der linken oberen Thoraxpartie, vorn und hinten. Anscultatorisch über den gedämpften Partien nur schwächeres Athmungsgeräusch als rechts. Iymphdrüsenschwellungen an verschiedenen Krörperregionen. Körpertemperatur 38, $6^{\circ}$ (4 $\mathrm{Uhr}$ Nachmittags). Keinerlei Cerebralerscheinungen (Motilitäts- oder Sensibilitätsstörungen, Schwindel, Pupillendifferenz u. $s$. w.).

Ophthalmoskopischer Befund (Dr. Braunschweig); Conturen der Papilia nervi optici rechts verschwommen, keine Staung der Gefässe. Druckschmerz auf dem rechten Tragus. Druckschmerzhaftigkeit und Anschwellung hinter dem rechten Ohre, durch welche die Ohrmuschel abgehoben wird. Das Trommelfell ist rechts wegen hochgradiger. Senkung der hinteren 
oberen häutigen Gehörgangswand bis zum Aufliegen nicht zu sehen. Links: Trübung jm hinteren oberen Quadranten. Flüsterzahlen rechts nicht einmal durch den Hörschlanch gehört, links 2 Neter. $G_{1}$ vom Scheitel nach rechts verstärlat. Geringe, aber ansgesprochene Hexabsetzung des rechten Ohres für hohe Töne. Urin zucker- und eiweissfrei.

Ordination: Klysma, Eisbeutel hinter das rechte Obr.

23. Mai. Gestern Abend gegen $6 \mathrm{Uhr}$ Schüttelfrost von etwa 20 Minuten Dauer, danach Temperatursteigerung bis $40,7^{\circ}$; heute Morgen wieder $37,7^{\circ}$.

24. Mai, Aufmeisselung rechts: Sehnitt durch die etwa $1 \mathrm{Cm}$. dick infiltrirten, lebhaft blutenden Weichtheile. Gefässlöcher an der typischen Stelle erweitert. Die Corticalis war nicht durchbrochen, wohl aber bestand ein fistulöser Durchbruch im lateralsten Theile der hinteren knöchernen Gehörgangswand nahe an der Spina supra meatum. Die typische Aufmeisselung entleert reichlich Eiter und Granulationen und schafft Zugang zu der Paukenhöhle, welcher noch erweitert wird. Nach hinten sondirt man von der Knochenhöhle aus durch eine Fistel ca. $1 \mathrm{Cm}$. tief in den Sinus transversus, welcher mit sehmierigeitrigen Massen erfullt ist. Die knöcherne Wand des Sulcus transversus wird ebenso wie die häutige Wand des Sinus transversus in ca. 20 Pfennigstückgrösse eröffnet und der breiige Inhalt des Sinus mit dem scharfen Löfel entfernt. Tamponade dieser Höhle mit Jodoformgaze, Drain in die Knochenhöhle, oben 2 Nähte.

24. Mai. Allgemeinbefinden gut, Kopfschmerzen verschwunden, Gestern Abend kein Schüttelfrost, aber Temperatur von $40,7^{\circ}$.

25. Mai. Gestern Abend $6 \mathrm{Uhr}$ Temperatur von 39\%. 1 Grm. Chinin. 7 Uhr Abends $40,7^{\circ}$ ohne vorhergegangenen Schüttelfrost. Keine Kopfschmerzen. Verbandwechsel; Spülwasser nach beiden Richtungen durchgängig.

26. Mai. Gestern Abend fieberfrei. Heute Morgen 37,80. Schüttelfrost nach der Operation noch nicht wieder dagewesen. Klage über geringe Kopfsebmerzen. Tägtich ein Klysma.

27. Mai. Gestern Abend Fieber von 39,1 1 Grm. Chinin. Klagt heute wieder über Kopfschmerzen im ganzen Kopf. Somnolenz stärker.

29. Mai. Klage über starke Kopfschmerzen; gestern Abend Erbrechen, Schüttelfrost, danach über $40^{\circ}$ Temperatur. Somnolent, aber klar. Hüstelt etwas, kein Auswur.

30. Mai. Gestern früh und ebenso Abends Schüttelfrost mittleren Grades. Hustet mehr, kein Auswurf. Klagt über Schmerzen in der linken Leistenbeuge, daselbst ist nichts Abnormes objectiv nachweisbar.

31. Mai. Schuttelfrost. Temperatur bis über $41^{\circ}$.

1. Juni. Selumerzen in der rechten Leistenbeuge. Schmerzen und Rothung des rechten Ellbogengelenks; Schmerzen im rechten Schultergelenk ohne Gelenkschwellung. Prominenz der Bulbi, mässige Divergenz der Sehaxen.

3. Juni. Gestern Schüttelfrost. Schmerzea in der rechten Schulter geringer. Ausgesprochene Neuritis optica beiderseits, links stärker als rechts (Dr. Braunschw eig); keine Abducenslähmung.

4. Juni. Oedem des rechten oberen Augenlides; Ptosis rechts, welche mechanische Folge des Oedems za sein scheint.

7. Juni. Oedem des rechten oberen Augenlides wieder verschwanden. Aussehen der Operationswunde sehr torpid.

9. Juni. Anschwollung der Halsgegend unterhalb der Operationswunde; 
durch Druck auf die Anschwellnng wird etwa ein Tassenkopf dünnflüssigen jauchigen Eiters aus dem unteren Winkel der Operationswunde entleert.

11. Juni. Gleiche Eitermenge entleert wie am 9. Juni. Gaumensegellähmung. Sprachstörung.

12.-15. Juni. Täglich emeute Eiteransammlung und Entleerung aus der seitlichen rechten Halsgegend unterhalb der Operationswunde.

15. Junj. Isst nicht, sehr somnolent. Hustet viel (Rasseln binten unten). Haemoptoe; nach Aussage der Warterin hat er $3-4$ Esslöffel hellrothen schaumigen Blutes unter kauenden Bewegungen entleert. In der Nacht die heftigsten Klagen über Kopfschmerzen. Er hat sich in die Lippe und Zunge gebissen, ohne dass von Convulsionen etwas bemerkt wurde.

16. Juni. Gestern Abend von $10 \mathrm{Vhr}$ stertoröses Athmen. $3 / 412 \mathrm{Uhr}$ Exitus letalis. Convulsionen waren vorher nicht beobachtet.

A utopsie: (Es konnte aus äusseren Grunden nur die Kopfsection gemacht werden.) Sinus phlebitis purulenta des Sinus transversus dexter, Sinus petrosus superior, Sinus cavernosus, Sinus Ridlei. Senkungsabscess in der rechten seitlichen oberen Halspartie; in demselben die verjauchte Vena jugularis. Weiter unten, d. h. von da an, wo der Senkungsabscess aufbörte, war die Vena jugularis gesund und mit Blnt gefüllt, die Intima intact. Meningitis purulenta beider Kleinhirnunterflächen. Der rechte Facialis- und Acusticusstamm schwamm in Eiter.

Oedema convexitatis. Das rechte Schläfenbein konnte der Leiche nicht entnommen werden.

Epikrise: Bei der Aufnahme in die Klinik konnte trotz des schweren Ohrleidens quoad vitam des Knaben Hessler eine relativ gute Prognose gestellt werden, weil keine sicheren meningitischen Erscheinungen vorhanden waren and weder die Anamnese noch auch der objective Befund das Vorhandensein einer eitrigen Sinusphlebitis wahrscheinlich machten. Die Trübung der Papilla nervi optici war das einzige suspecte Zeichen, welches an die Möglichkeit des Entstehens resp. schon Vorhandenseins einer intracraniellen Erkrankung mahnte. Die Diagnose eitrige Sinusphlebitis wurde indess durch den Schitttelfrost am Tage vor der Operation in hohem Grade wahrscheinlich und durch den Operationsbefund vollauf bestätigt. Die Operation war insofern von gïnstigem Einfluss, als der Kranke sicb nach ihr wesentlich erleichtert fühlte, die heftigen Kopfschmerzen für einige Tage verschwanden, er weniger somnolent war und regeren Appetit bekam. Indess war die Operation auf den weiteren Verlauf des Krankheitsprocesses ohne Einfluss. Die sich häufig wiederholenden Schüttelfröste, der Fieberverlauf mit den hohen Remissionen, die Metastasen zeigten das typische Bild der Pyämie. Die eitrige Meningitis an den unteren Flächen beider Kleinhirnhemisphären batte ihrer Localisation entsprechend in vita keine prägnanten 
Erscheinungen gemacht. Die Frage, wann diese Complication hinzugetreten ist, kann nicht entsehieden werden. Die Propagation der Ohreiterung in den Schädel hat wohl durch das Labyrinth und dann den Porus acusticus int. stattgefunden (vgl. Sectionsbefund). Bedanerlich ist, dass eine gründliche Seetion des betreffenden Schläfenbeins nicht vorgenommen werden konnte. Der Hörprïfungsbefund bei der Aufnahme, insbesondere die Herabsetzung des rechten Ohres für hohe Töne, liessen an die Möglichkeit einer bereits stattgefundenen Ausdehnung der Eiterung anf das innere Obr denken. Der Sectionsbefund nimmt unser Interesse noch in zweifacher Riehtung in Anspruch: erstens dadurch, dass er uns zeigt, dass auch bei einer so schweren Erkrankung die Tendenz zu einer Naturbeilung besteht (verjauchtes Stiuck der Vena jugularis in dem Senkungsabseess), und andererseits, dass aus anatomischen Gründen die von Zaufal 1880 vorgeschlagene Unterbindung der Vena jugularis bei eitriger Sinusthrombose nicht immer eine Abschliessung des Erkrankungsherdes von den Körperblutbahnen bewirken kann. In diesem Falle hatte sich die eitrige Sinusthrombose weiter nach vorn auf den Sinus petrosus sup., Sinus cavernosus, Sinus Ridlei fortgepflanzt (vgl. Prominenz der Bulbi, Oedem des rechten oberen Augenlides) und war jedenfalls von der Vena jugularis sinistra die Aufnahme der zerfallenen Thrombenmassen in die Blutbahn erfolgt, was deshalb in hohem Grade wabrseheinlich ist, weil die rechte Vena jugularis unterhalb des Senkungsabseesses vollkommen intact und nach oben vollkommen abgeschlossen war. In diesem Falle wäre mithin die Unterbindung der Vena jugularis dextra für den weiteren Krankbeitsverlauf ganz irrelevant gewesen.

4. Paul Strietzel, 13 Jahre alt, Vater Walkereibesitzer in Cottbus. Rec. 26. Juni 1891. Ohreiterung beiderseits seit frühester Kindheit aus unbekannter Ursache; nie sind im Verlauf der Otorrboe acute Exacerbationen dagewesen. 5 Tage vor der Aufnabme plotzlich heftige Schmerzen im linken Ohr, Druckschmerz vor und hinter dem Ohr. Kein Schlaf seit der Zeit. Kopfschmerzen in der linken Kopthälfte. Kein Schwindel, kein Schüttelfrost, Mundathmen, Erblich nicht nachweisbar belastet.

Status praesens: Kein Sehwindel beim Stehen oder Gehen mit geschlossenen Augen. Sehr flachbrüstig, aber keine sicheren Zeichen für Lungenphthise. Herz gesund. Temperatur Abends 6 Uhr $39,2^{\circ}$, am 27. Juni Morgens $38,1^{\circ}$. Puls 104, intermittirend. Starker Druekschmerz vor und hinter dem linken Ohr. Leichte Empfindlichkeit der linken Jugularisgegend gegen Druck. Links: Gehörgang normal weit, Trommelfell blauroth, abgefiacht, Proc. brevis angedeutet, vom Hammergrifi nichts zu sehen. Perforation eng, 
in vorderen unteren Quadranten gelegen. Fötide Otorrhoe. Rechts: Fö. tide Eiterung, in der Tiefe weisse Hautcoulissen. Flästerzahlen links $4 \mathrm{Cm}$., rechts $22 \mathrm{Cm}$. Hohe Töne beiderseits deutlich, $\mathrm{C}_{1}$ vom Scheitel nach links verstärkt. Beim Cath. tubae links Perforationsgeräusch mit Rasseln, rechts sehr hohes Perforationsgeräusch mit Rasseln. Hochgradige linksseitige Tonsillenhypertrophie.

Ordination: Lavement, Eis, Sublimatausspülungen $(1,0: 10,000)$ des Gehörganges.

27. Juni. Aufmeisselung links: Paracentese links, resp. Dilatation der zu engen Perforation im Trommelfell. Weichtheile stark infiltrirt; nach dem Zurückschaben des Periostes kommt Eiter zum Vorschein, welcher aus einer feinen Fistel etwas unterhalb der tzpischen Durchbruchsstelle hervorquillt. Das Antrum wird typisch eröffnet und zeigt sich angefüllt mit zerfallenen fötiden Cholesteatommassen. Ausräumung des zerfallenen Cholesteatoms mit dem scharfen Löffel. Fortnahme der hinteren knöchernen Gehörgangswand. Spaltung der hinteren häutigen Gehörgangswand in horizontaler Richtung. Tamponade.

28. Juni. Fieber und schmerzfrei.

29. Juni. Fruth, nach unruhiger Nacht, $38,6^{\circ}$ Temperatur. Verbandwechsel, Foetor.

6. Juli. 3 Tage lang bestand Abends geringes Fieber; heute Abend fieberfrei. Durehspülung links durch den Katheter.

11. Juli. Fieber- und schmerzfrei. Im Uebrigen st. idem.

15. Juli. Sehr viel Neigung zum Schlafen. Starker Torpor cerebri. Zuweilen Klage über Kopfschmerz. Ausgesprochene Pulsverlangsamung (48).

16. Juli. Brechneigung nach dem Essen.

19. Juli. Die Pulsverlangsamung war täglich constatirbar. Im Uebrigen ausser starker Schlafisucht keine weiteren Cerebralsymptome heute constatirbar.

20. Juli. Sehr somnolent, aber klares Bewasstsein. Kopischmerzen diffus, allgemeine Hyperästhesie der Haut. Keine abnormen Erscheinungen seitens der Motilität. Neuritis optica beiderseits.

27. Juli. Früh $40,9^{\circ}$. Keine Convulsionen. Exitus letalis früh 10 Uhr unter den Erscheinungen von Lungenödem.

Kopfsection: Grosser schwappender Abscess im linken Schläfenlappen, der grünen fötiden Eiter enthält. Dicke, von der gesunden Umgebung leicht abziehbare, schon schwielige Abscessmembran. Keinerlei Zeichen von Basilaroder Convexitätsaeningitis. In der rechten Kleinhirnhälfte ein etwa erbsengrosser, knochenharter Tumor, dessen mikroskopische Untersuchung noch aussteht. (Verkalkter Abscess?)

Die Schläfenbeine konnten der Leiche nicht entnommen werden.

Epikritische Bemerkungen: Auffallend war von rornherein die Intermittenz des Pulses, welche sich auch diesmal als ein prognostisch sehr böses Zeichen erwies.

Suspect für einen Hirnabscess war die ansgesprochene Pulsverlangsamung, welche constant vom 14. Juli an beobachtet wurde, ferner der Kopfsehmerz, der diffus war, und die Brechneigung. 
Eine Localisation des Hirnabscesses war deshalb unmöglich, weil keine Percussionsempfindichkeit und keine motorischen und sensiblen Störungen bestanden. Es war nicht einmal mit Wahrscheinlichkeit zu bestimmen, auf welcher Seite die intracranielle Erkrankung localisirt war, bestand doch auch auf dem rechten Ohr eine schwere chronische Eiterung, welebe ebenso gut wie das linke $\mathrm{Ohr}$ den Abscess inducirt haben konnte. Dass ein Hirnabscess vorlag, daran zweifelten wir nicht und waren auch zu einem operativen Eingriff entschlossen. Es iiberraschte uns aber der ziemlich plötzliche Eintritt des Todes in der Zeit, welche noch der Beobachtung darauf, ob sich noch Erscheinungen einstellen würden, welche eine Localisation des Krankheitsherdes gestatteten, gewidmet war. Wäre in diesem Falle rechtzeitig auf den linken Schläfenlappen trepanirt, so wären die Chancen, dem Kranken das Leben zu erhalten, äusserst günstig gewesen. Denn einmal lag der Eiterherd so oberflächlich und war so ausgedehnt, dass man ihn ohne Schwierigkeit erreicht hätte, und andererseits hätte man die Abscessmembran, welche den Abscess vollkommen abkapselte, leicht in toto herausschälen und so den ganzen Krankheitsherd vollkommen eliminiren können. Was das Alter des Abscesses anbetrifft, so ist nach der Dicke der Membran und nach der bereits sebwieligen Beschaffenheit derselben anzunehmen, dass er wenigstens 6 Wochen alt war, also schon bei der Aufnahme des Kranken in die Klinik bestanden hat. Aat welchem Wege die Propagation der Eiterung vom $0 \mathrm{hr}$ nach dem Cerebrum zu Stande gekommen ist, konnte nicht genau constatirt werden, weil eine Section des linken Schläfenbeins aus äusseren Gründen nicht möglich war.

5. Hermann Tempel, 21 Jahre alt, Bergmann in Vaterode bei Mansfeld. Rec. am 15. September 1891. Chronische Eiterung rechts mit purulenter Sinusthrombose. Otorrhoe rechts, angeblich erst seit einem Jahre. Seit 12. September Kopfschmerz, Schwindel, Schüttelfröste mit kaltem Schweiss, Appetitlosigkeit.

Status praesens: Status typhosus, belegte Zunge, grosse Mattigkeit, Schwindel schon beim Aufsitzen im Bett. 39,8 Temperatur, Puls 118, regelmässig. Der rechte Processus mastoideus ist, ohne dass seine Weichtheile infiltrirt sind, auf Druck ausserordentlich schmerzhaft; ebenso ist die ganze rechte Halsgegend, dem Verlaufe der Vena jugularis entsprechend, schon bei leisester Berührung ausserordentlich empfindlich. Der rechte Gehörgang ist voll Eiter. Das Trommelfell ist abgeflacht, hinten oben polypöse Wucherung. Das linke Trommelfell ist normal. Hörprüfung unzuverlässig wegen der Somnolenz. Flüsterzahlen scheint er rechts $20 \mathrm{Cm}$., links 3 Meter weit zu hören. Fis 4 beiderseits deutlich (?). $\mathrm{C}_{1}$ unbestimmt. 
16. September. Aumeisselung rechts: Nach dem Zurückschieben des Periostes zeigt sich die Oberfläche des Knochens von der Norm sehr abweichend: die stark ausgepragte Linea temporalis stand so tief, dass ihre Verlüngerung nach dem Meatus zu die Spina supra meaturn etwa halbirt haben wurde. Typische Aufmeisselung des Antrum mastoideum. Dasselbe lag sehr tief und war mit Granulationen und cholesteatomatösen Massen erfült. Bei der Anlegung des Operationskanales wurde der Sinus transversus blossgelegt. Er war grünlich verfärbt and wurde umspült von jauchiger, bräunlicher, lebhaft pulsirender Flüssigkeit. Der Knochen zeigte sich an der dem Sinus entsprechenden Stelle schwärzlich verfärbt und zerfressen. Fortnahme der hinteren knöchernen Gehörgangswand. Entfernung von Amboss - der kurze Schenkel war durch Caries zerstört - and Hammer mit der Pincette. Spaltung der häutigen hinteren Gehörgangswand nach Stacke. Tamponade.

19. September. Ansgesprochener Schüttelfrost; danach eine Temperatur von $40,9^{\circ}$. Schmerzen in der linken Brusthälfte.

21. September. Patient liegt stöhnend im Bett. Verbandwechsel. Der verfärbte Sinus transversus wird, nachdem mit einer Aspirationsnadel festgestellt war, dass er Eiter enthielt, incidirt, der eitrig zerfallene Thrombus mit 1,0:10,000 Sublimatlösung ausgespült und, soweit sich bei dem Spülen die Thrombenmassen entlecrt hatten, mit Jodoformgaze austamponirt.

22. September. Geringe DJspnoe. Rasseln auf der linken Pleura.

23. September. Abends 11 Uhr Exitus letalis.

Antopsie. Diagnosis post mortem: Thrombose des Sinus transversus dextr. und der Vena jugularis dextr., Pachymeningitis partial. fibros. chron., Pleuritis purul. sin. putrida (Emphysem und Pneumopyothorax), Atelectasis pulmon. sinistr., Bronchopneumon. pulmon. sinistr., Pleuritis fibrinos. dextr. recens., Infarct. hämorrhag. pulmon. dextr., Pneumonia c. part. pulwon. dextr., Oedema part. pulmon. dextr.

Mässig gut entwickelte männliche Leiche. Rigor vorhanden. Keine Oedeme. Hautdecken im Allgemeinen blass; an den abhängigen Partien zahlreiche Todtenflecke. Proe. mastoidens ist rechts breit eröffnet; dem Sternocleidomastoideus entsprechend zieht sich eine $10 \mathrm{Cm}$. weite Schnittwunde entlang, deren Pänder gutes Aussehen zeigen. Schädeldach dünn, gut gowölbt. Aussenfläche der Dura stark vaseularisirt, die Gefässe stark mit Blut gefüllt; im Sinus longitudin. ein dunkelrothes Gerinnsel. Dura mässig gespannt, auf der Innenseite obne Auflagerungen. Die Venen der Pia sind bis zur vollen Rundung gefullt; uber den Sulci ist die Pia leicht getrubt, mit einzelnen weissen Flecken besetzt. Der rechte Sinus transversus ist mit grüngelben puriformen Massen ausgefullt. Die Dura der hinteren Schädelgrube rechts stark verdickt, auf der Innenfläche stark vascularisirt. Auf der Aussenfläche der Sinus mit fest haftenden gelblichen Auflagerungen versehen. Die Arterien der Basis sind leer, haben weiche Wandung. Pia der Basis stark vascularisirt, ohne Besonderheiten. Die rechte Kleinhirnhemisphäre ist uberdeckt mit stark entwickelten, bis zur vollen Rundung gefüllten Gefässen. In den Seitenventrikeln geringe Mengen klarer Flüssigkeit. Hirnsubstanz ron fester Consistenz. Im Centrum semiovale zahlreiche Blutpunkte, die nach dem Abspülen wieder sichtbar werden. Auch die graue Substanz lässt auf dem Durehschnitt Blutpunkte erkennen. Grosse Ganglien ziemlich blutreich. Pons und Medulla ohne Besonderheiten. 
Nach Eröffnung der Bauchhöhle bedeckt das zarte Netz die Dünndarmschlingen. In den vorderen Partien sind die Därme mehr gran, in den hinteren mehr gallig. Zwerchfell stand links an der fünften, rechts an der sechsten Rippe. Nach Fortnahme des Brustbeins dringt aus der rechten Pleurahöhle röthliche Flüssïgkeit, aus der linken Gase, die stark nach Schwefelwasserstoff riechen, und eine grüngelbliche, mit groben Flecken gemischte Flüssigkeit. Rechte Lunge vollkommen freiliegend, die linke sehr geschrumptt, in den oberen Theilen durch strangförmige Adbäsionen in der Gegend der Wirbelsäule adhärent. Das Lungenparenchym lässt sich einige Millimeter weit in die Adhäsionen verfolgen. In der linken Pleurahöhle etwa 1 Liter chocoladefarbener Flüssigkeit.

Herz liegt in ganzer Ausdehnung frei. Im Herzbentel ca. $40 \mathrm{Ccm}$. mit groben Fibrinflocken gemischter, sonst klarer Flüssigkeit. Aorta sehr eng: Klappen schlussfähig und zart. Musculatur von intensiver Röthe. Costalund Lungenpleura links mit ausgedehnten dicken, grünlich gefärbten Beschlägen, nach deren Entfemung unter der Pleura entfärbte kleine Blutanstritte sichtbar werden. Lunge ist rollkommen laftieer, sinkt in toto nnter. Pigmentirung anf dem Durehschnitt deutlich. Lymphdrüsen auf dem Durch: schnitt schiefrig pigmentirt.

Lungenpleura rechts stark vascularisirt, sehr trocken. Die gröberen Verzweigungen der Bronchien sind mit schaumiger Flüssigkeit gefüllt. Mucosa stark vascularisirt und blutig suffundirt. Am freien Rande des Unterlappens ein ca. hühnereigrosser, dunkelgefärbter, zum Theil erweichter, gegen die Umgebung scharf abgegrenzter Herd. Im Unterlappen ist auch die Lunge stellenweise atelectatisch. Mittellappen leicht ödematös.

Milz mit zarter Kapsel lässt auf dem Durchschnitt keine Zeichnung erkennen. Linke Niere mit normal weitem Ureter, leicht löslicher Kapsel. Parenchym stark bluthaltig. Auf dem Durchschnitt obne Veränderungen. Rechte Niere verhält sich entsprechend.

Blase stark gefullt. Schleimhaut mit vorspringenden Trabekeln.

Im Magen viel trübe Flüssigkeit. Schleimbant des Magens in Falten gelegt; im Fundus stellenweise erweicht.

Leber gross, fettreich, acinöse Zeichnung dentlich, leichte Staunng, In der Gallenblase dunkelgrüne Galle mit zahlreichen Krystallen.

Section des rechten Schläfeubeins: Fom Trommelfell nur ein peripherischer Saum vorn unten erbalten, Hammer und Amboss nicht vorhanden (cf. Operationsbericht), Steigbügel in situ. Die Paukenschleimhaut zeigt sich polsterartig verdickt, die Knochenwände unter ihr erscheinen nirgends erkrankt. Am Tegmen tympani nichts Abnormes. Die Wand des Sulcus transversus ist cariös durchbrochen in Gestalt einer runden Oeffnung von $1 \mathrm{Cm}$. Durchmesser. Die bei der Operation borizontal gespaltene häutige hintere Gehörgangswand ist im medialen Theille wieder verwachsen, so dass ein geschlossenes Roh" entstanden ist mit einem ovalen Loch im lateralen Theile, durch welches man in die künstlich excavirte Knochenhöhle des Warzenfortsatzes, resp. des Antrum mastoideum sieht. Die das Foramen mastoideum durchsetzende Vene ist thrombosirt.

6. Ueber den Fall Schmidt, welcher am 2. Mai 1892 an einem ausgedehnten Osteosarkom der Schädelbasis in unserer Klinik zu 
Grunde ging, ist von Herrn Dr. Schwidop, Volontärarzt der Klinik, in diesem Archiv ausführlich berichtet worden (Bd. XXXV S. 39).

Wir wollen im Folgenden einige der interessanteren Fälle hervorkeben.

Friedrich Rohrmann, 59 Jahre alt. Carcinom der Ohrmuschel. Infolge einer Quetschung soll an der Grenze des oberen und mittieren Drittels des Ohrmuschelrandes eine Warze entstanden sein, welche hornartig wurde, allmählich wuchs und vor etwa einem Vierteljahre zu ulceriren begann. Zeitweilig traten stechende Schmerzen anf. Die oberen 2 Drittel der Ohrmuschel sind von einem lappigen ulcerirenden Tumor eingenommen, der übrige Theil ist starr infiltrirt, nach vorn vor dem Ohre ein infiltrirtes Drüsenpacket. Gehörgang und Trommelfell normal, ebenso mittleres and inneres Ohr. Nachdem durch die mikroskopische Untersuchung die Diagnose Epithelialkrebs gesichert war, wurde am 23. März operirt. Ein bogenförmiger Schnitt, ca. $2 \mathrm{Cm}$. hinter dem $\mathrm{Ohr}$ mit einem ebensolchen ca. $2 \mathrm{Cm}$. vor dem Tragus, entfernte das ganze $\mathrm{Ohr}$ mit Zellgewebe bis auf die Fascia temporalis und die erreichbaren Drüsen fast bis zum Beginn des knőehernen Gehörganges. Nach sorgfältiger Unterbindung der reichlichen spritzenden Gefässe wurde, am den so entstandenen elliptischen Substanzverlust zu decken und Stenose des Gehörganges zu verhindern, ein dem hinteren Schnitt fast paralleler, nur weniger gebogener Entspannungssehnitt geführt, die so entstandene Hautbrücke mit den Weichtheilen abpräparirt und nach vorn verzogen. Sodann wurde die obere und die untere Ecke des Defectes durch straffe Nähte geschlossen und Entspannungsnähte möglichst genähert und die Mitte der Schnitte an den Rest des knorpeligen Gehörganges so angenäht, dass die Epidermis des Gehörgangs mit der der äusseren Haut fest zusammenlag. Die Vereinigung der Wundränder erfolgte per primam, soweit genäht war, und der hỉntere sichelförmige and die beiden dreieckigen Defecte über und unter dem Gehörgang fülten sich mit Granulationen, welche bis zum 12. April, also in 21 Tagen, vollständig mit Epidermis überzogen waren. Der Gehörgang ging ringsum lippenförmig in die äussere Epidermis über; das normale Trommelfell war direct von aussen sichtbar ohne Reflector.

\section{Fall von Heilung einer sehr schweren Pyämie ex otitide.}

Emil Höfer, 14 Jahre alt, Vater Arbeiter in Halle. Rec. am 17. November 1891. Früher stets ohrgesund. Seit 4 Jahren im Anschluss an Typhus abdominalis Ohreiterung rechts. Im Verlauf der Otorrhoe hin und wieder Schwindel. Einige Tage vor der Aufnahme in die Klinik Ohrenschmerzen rechts und Zunahme des Schwindels. Schwellung der Gegend um das rechte $\mathrm{Ohr}$ herum, Oedem und Drackempfindlichkeit auf dem Warzenfortsatz. Dem Verlauf der Jugularis entsprechend keine Druckempfindlichkeit. Der rechte Gehörgang zeigt sich concentrisch entzündlich verengt, das Trommelfell ist sichtbar und zeigt im vorderen unteren Quadranten eine kleine Perforation. Links: normal. Flüsterzahlen rechts $15 \mathrm{Cm} . \mathrm{C}_{1}$ vom Scheitel nicht nach rechts verstärkt angegeben. Fisf rechts nur bei stärkerem, links bei leisestem Anschlag. Beim Cath. tubae rechts Perforationsgeräusch mit Ras- 
seln. Mässige adenoide Vegetationen. Temperatur am 17. November Abends $38,9^{\circ}$, am 18. November Morgens $39,6^{\circ}$.

Ordination: Eissbeutel auf den Warzenfortsatz. Klysma.

19. November 1891. Aufmeisselung rechts: Beim Schnitt durch die Weichtheile entleerten sich etwa 4 Esslöffel dankelbrauner, sehr fötider dünner Jauche. Nach dem Zurückschieben des Periostes zeigt der Knochen in etwa Markstückgrösse in der Gegend der typischen Spontandurchbruchsstelle eine grau-bläuliche Verfärbung und hat erweiterte Gefässlöcher. Einige Linien nach aussen und unten ron der Spontandurchbruchsstelle findet sich eine stecknadelkopfgrosse morsche Partie; ein grösserer Durchbruch, in welchen man mit der Sonde hätte einaringen können, war nicht vorhanden. Die Ohrmuschel wurde so weit vorgeklappt, dass die Wurzel des Arcus zygomaticus frei lag, ohne dass hier irgendwo Eiter gefunden wurde. Bei der nun begonnenen typischen Aufmeisselung wurde bei den ersten Meisselschlägen der abnorm weit nach vorn liegende verfärbte Sinus transversus freigelegt, zwischen dessen Wandung und dem Knochen Eiter hervorquoll. Wegen dex Verlagerung des Sinus transversus nach vorn wurde das Antrum vom Gehörgange aus durch Fortnahme concentrischer Schichten der hinteren lnöchernen Gehörgangswand eröffnet. Die Knochenzellen waren vielfach mit Eiter erfüllt. Der Hammer und Amboss wurden von hinten extrahirt. Der Sinus transversus wurde durch Fortnahme der ihn noch bedeckenden cariosen Knochenwand so weit freigelegt, dass er in etwa 10 Pfennigstückgrösse offen lag und der perisinöse Eiter freien Abfluss hatte. Entfernung der Abscessmembran in den den Warzenfortsatz bedeckenden Weichtheilen, Spaltung der häutigen binteren Gehörgangswand nach Stacke; 2 Nähte im oberen Mundwinkel, Tamponade mit Jodoformgaze.

Die Operation hatte auf den weiteren Verlauf der typischen Pyämie keinen erkennbaren Einfluss, es folgte Schüttelfrost auf Schüttelfrost, das Fieber war durchweg sehr hoch, am 20. November Abends wurde sogar die excessive Höhe von $41,7^{\circ}$ erreicht, die Ordination bestand in Chinin und Wein in grossen Quantitäten. Trotz der schweren Erseheinungen und trotz des Hinzukommens einer acuten Endocarditis trat vollkommene Genesung ein. Am 14. Januar 1892 konnte der Kranke zu poliklinischer Weiterbehandlung, in welcher auch sein Ohrenleiden ausheilte, entlassen werden.

Wir traten in diesem Falle der Frage näher, ob noch nachträglich nach der Aufmeisselung des Warzenfortsatzes nach dem Z a ufal'sehen Vorschlage die Vena jugularis unterbunden werden sollte. Mit der Ausfuhrung der Unterbindung der Vena wurde indess gezögert, wohl deshalb, weil wir noch unter dem Einfluss des Eindruckes standen, welchen das Sectionsergebniss des wenige Monate vorher an Pyämie verstorbenen Knaben Hessler (vgl. S. 242 ff.) auf uns gemacht, wo eine Ausbreitung der Sinusthrombose nach der anderen Seite a priori den Erfolg einer Venen- 
unterbindung zu einem illusorischen gemacht hätte. Schliesslich wurde bestimmt, dass die Unterbindung ansgefiibrt werden sollte, sobald sich noch ein einziger Schiittelfrost einstellte. - Dieser Schüttelfrost blieb aber ans. Wäre in diesem Falle die Unterbindung erfolgt, so wäre man jedenfalls geneigt gewesen, die Heilung einer so schweren Pyämie anf Rechnung der Unterbindung zu setzen.

Robert Bischof, 17 Jabre alt. Seit dem 4. Lebensjahre beiderseits Eiterung nach Masern, welche bis jetzt fortbestand. Oefters Kopfschmerz und leichter Schwindel, kein Erbrechen; seit dem 9. August trat Schwellung hinter dem rechten Ohre auf. Trotz Blutegel und Eis nahmen die Schmerzen so zu, dass sie Schlaflosigkeit verursachten, öfters sollten Schüttelfröste anfgetreten sein. Beide Eltern sind brustleidend. Patient hatte öfters scrophulöse Drüsenanschwellungen.

Status: Caput obstipum nach rechts. Die ganze rechte Schädelhälfte, Wange und Hals geschwollen, heiss und auf Druck schmerzhaft, der rechte Gehörgang voll dicken Eiters und schlitzförmig von vorn oben nach hinten unten verengt. Den 12. August Spaltung des über den halben Schädel gehenden Abseesses. Unter dem Periost quillt furchtbar stinkende Jauche herror. Durchbruch an der üblichen Stelle der Aufmeisselung und an der Spina. Daselbst ist die Corticalis morsch wie faules Holz. Bei der Ausmeisselung des kranken Knochens wird die hintere Schädelgrube in Ausdehnung von $3: 1$, die mittlere von $1: 1 \mathrm{Cm}$. weit freigelegt. Dura nicht verfärbt, Sinus pulsirend. Nach dem Nacken zu wird durch einen ca. $6 \mathrm{Cm}$. langen Schnitt ein jauchiger Abscess freigelegt. Von der so freigelegten Kopfschwarte wird die Abscessmembran mit scharfem Löffel und Coop er'scher Scheere entfernt. Die ganze hintere Gehörgangswand und die Spitze des Proc. mast. wird weggeschlagen. Die Parietalschuppennaht war theilweise verfärbt und wurde flach abgemeisselt. Spülen mit Sublimat $1: 1000$, Naht der beiden Schnitte bis auf eine Oeffnung für ein Jodoformgazedocht, Tamponade der Wunde mit Jodoformgaze.

Abends Oedem des Augenlides, Temperatur 39,90. Seitdem fieberirei. 27. August. Die Wunde hat sich gut gereinigt, der Sinus pulsirt und ist mit Granulationen bedeckt. Am 21. October wurde der cariöse Hammer entfernt, am 5. November musste Patient mit ganz geringer geruchloser Eiterung entlassen werden.

Ein treffendes Beispiel, wie viel Vorsicht bei der Beurtheilung des Heilungsresultates geboten ist, und welch inniger Znsammenhang zwischen den Erkrankungen des Antrum und der Pankenhöhle besteht, bietet der folgende Fall:

Jochen Dzadeck, 6 Jahre alt. Seit 5 Wochen Eiterung links nach Masern; Ohrmuschel rechtwinklig abstehen!. Unter dem Sternocleidomastoideus eine geschwollene Lymphdrüse. Nur bei stärkerem Druck besteht Schmerzhaftigkeit des Warzenfortsatzes. Gehörgang voll gelbgrünen fötiden Eiters, welcher bei Druck auf die Schwellung hinter dem Ohre langsam her- 
vorquillt, breites Perforationsgerăusch and Rasseln. Flüsterzahlen nicht ins Ohr.

17.-20. November. Snblimatspulung, Eis ad proc. mast. Die Eiterung, Schwellung und der Druckschmerz geht anter dieser Behandiung zurück.

Am 24. November ist selbst bei stärkstem Druck der Warzenfortsatz nicht mehr empfindlich. Das Ohr trocken, der Gehörgang noch etwas verschwollen, so dass nur der hintere obere Theil des blaugrauen Trommelfelles sichtbar ist. Bei Luftdouche Rasseln in der Panke. Am 26. November tritt an der Hinterwand ein seheinbarer Furunkel auf, der das ganze Krankheitsbild verursacht zu haben schien.

Am 28. November sind die Rănder seiner Oeffnung granulös geworden; am 30. November tritt wieder breites Perforationsgeräusch und Rasseln auf.

Am 3. December ist ein subperiostaler Abscess auf dem Proc. mast. vorhanden und die hintere obere Gehörgangswand gesenkt. Bei der nunmehr vorgenommenen Aufmeisselung zeigt sich die Corticalis in etwa Markstückgrösse cariös, am Beginn des knöchernen Gehörgangs, etwa der Fistel im häutigen entsprechend, ein Durchbruch, durch welchen man in eine ziemlich glattwandige, mit Eiter und Granulationen erfüllte, bis in die Spitze und ins Antrum reichende Böhle kommt. Dieselbe wird breit eröffinet, die Durchbruchsstelle im Gehörgang excidirt. Spülwasser war frei durchgängig. Vom 24. December an Ohr trocken, Wunde geschlossen; $\mathrm{C}_{1}$ vom Scheitel nach links, Fis 4 deutlich. Flüsterzahlen $3 / 4$ Meter.

Ein weiteres Beispiel dafur, welche Vorsicht geboten ist bei der Entscheidung der Frage, ob eine chronische Mittelohreiterung wirklich, d. h. dauernd geheilt ist, oder ob nur eine Scheinheilung vorliegt, bietet der folgende Fall:

Ernst Henke 1, 20 Jahre alt, Uhrmachergehülfe in Könnern. Rec. 20. October 1891. Chronische Eiterung rechts, Residuen links. Seit frühester Kindheit besteht Ohreiterung rechts mit Schwerhörigkeit von gleichbleibender Intensitāt. Vor 3 Jahren bekam Patient links eine Ohrfeigenruptur. Bei Behandlung derselben in unserer Klinik wurde durch Galvanokauterisation einer Granulation, welche das rechte Trommelfell durchwachsen hatte, die rechtsseitige Otorrhoe vermindert. Nach einem Jahre begann das rechte Ohr wieder stărker zu eitern; es traten Ohren- und Kopfschmerzen, Schwindel, unruhiger Schlaf und offteres Uebelsein auf. Der Vater starb an Diabetes mellitus und Phthisis pulmonum. Links: Narbe im hinteren unteren Quadranten des Trommelfelles. Rechts: Spärliche, aber fötide Eiterung. Der Hammer ist retrahirt. Finten oben Ablösung des Trommelfelles und Durchbruch der knöchernen hinteren Gehörgangswand. Flüsterzahlen rechts $50 \mathrm{Cm}$, links 5 Meter. $\mathrm{C}_{1}$ vom Scheitel nach rechts verstärkt, Fis4 beiderseits deutlich. Beim Cath. tubae beiderseits Blasegerăusch. Die fötide Otorrhoe kam anter tăglichen Ausspülungen des Antrum mast. mittelst des durch den Durchbruch in der knöchernen Hinterwand eingefuthhten Antrumröbrchens und folgender InstalJation von Tetraborsäure (Jänicke) nach 17 Tagen zum vollkommenen Stillstand. Der Patient wurde 7 Monate lang regelmässig controlirt, und das Ohr machte stets den Eindruck der eingetretenen Heilung. Im Juni 1892, also nach 7 Monaten, trat ein Recidiv der Eiterung ein. Der operative Eingriff, 
welcher nun vorgenommen wurde, stellte eine ausgedehnte Caries im Aditus ad antrum und im Antrum fest. Ebenfalls war der Amboss cariös.

Es ist ganz vortheilhaft, casuistisches Material zusammenzutragen, welches lehrt, wie vorsichtig man bei der Beurtheilung seiner therapentischen Erfolge einer alten Ohreiterung gegenuiber sein muss, wenn man verhängnissvolle Irrthtumer vermeiden will. Wenn man solche Fälle erlebt hat, wird man einen gewissen Skepticismus nicht unterdriicken können "Erfolgen" gegeniuber, wie sie nach Publicationen in der otologischen Literatur so vielfach in der Behandinng chronischer Ohreiterungen mit and ohne Caries in fabelhaft kurzer Zeit und bei einer äusserst einfachen palliativen Behandlung erzielt werden.

Friedrich Diesing, 28 Jahre alt. Eiterung seit 14 Jahren nach Maseru, öfters Kopfschmerz, beim Bülen Schwindel. Oefters ist durch Aetzen mit einem Höllensteinstift versucht worden, Polypen im Gehörgang zu beseitigen. Das Resultat war rechts eine Missstaltung der Ränder des Gehörganges, links eine kaum linsengrosse Stenose, welche durch einen Polypen völlig obturirt war. Für Affection des Warzenfortsatzes und des inneren Ohres bestanden keine Zeichen. Am 22. Januar wurde zunächst eín Polyp von der Grösse des letzten Daumengliedes mit einer der Stenose entsprechenden Schnürfurche extrahirt, dann durch 3 radiäre Incisionen 3 Lappen aus der Steuose gebildet. Von diesen wurde der centrale Rand durch parallele Schnitte in Keilen excidirt und die Seiten der so entstandenen Substanzverluste durch Naht geschlossen. Die Schnitte heilten fast ganz per primam bis auf leichte Granulationsbildung an den Rändern und eine kleine Knorpelnekrose an einer Stelle. Nach mehrmaliger Polypenextraction, Aetzungen und aseptischen Durchspülungen, sowie Anwendung ron Jodoformpulver, sistirte die Mittelohreiterung beiderseits am 16. April, Im Juli 1892 wurde das Fortbestehen der Heilung constatirt. Der ehemals stenosirte Gehörgang war normal weit geblieben, ringsum überbäutet.

Friedrich Koch, Schäfer, 56 Jahre alt. Lupus der Ohrmuschel. Vor etwa 10 Jahren begannen sich an der linken Ohrmuschel kleine Schorfe zu bilden, welche năssten und Blut und Eiter absonderten. Das ganze linke Ohr ist starr infiltrirt, ekzematös und ebenso wie die Umgebung mit zahlreichen Lupusknötchen durchsetzt. Der Lobulus, narbig infiltrirt, hängt nur noch dureh einen dünnen Stiel mit dem Ohr zusammen. Der mediale Theil des Gehörganges und das Trommelfell ist elzzematös.

9. September. Cauterisiren der lupösen Partien mit dem Paquelin und Abtragen des degenerirten Lolvulus. Die Operation genügte nicht zur Heilung. Deshalb wurde am 9. October $1 \mathrm{Mgrm}$. Tuberculin injicirt, am 12. October $2 \mathrm{Mgrm}$., am 19. October 4 Mgrm., am 27. October $8 \mathrm{Mgrm}$. Die ersten drei Injectionen blieben ohne jede Reaction, die vierte verursachte $38,3^{\circ}$ Fieber, etwas Rückenschmerzen ohne subjective oder objective Locaireaction.

Infolgedessen wurde am 29. October das lupöse Gebiet mit dem scharfen Löffel möglichst ausgiebig ausgekratzt und mit dem Paquelin gebrannt, nach 
einigen Tagen musste wegen einer Nachblutung der Verband gewechselt und ein spritzendes Gefäss unterbunden werden. Die Wunde granulirte und epidermisirte gut ausser am vorderen Pand, welcher trotz wiederholten Auskratzens, Aetzens mit Höllenstein und Jodoformeinpuderns immer noch unterminirte Rănder behieit. Deshalb wurde am 17. November 8 Mgrm., am 4., 5., 11., 14. December je 1 Cgrm. Tuberculin injicirt, ohne Fieber- oder locale Reaction, nur einmal Rḯckenschmerzen verursachend. Am 15. December Abends Temperatur $39,5^{\circ}$, nacbdem Patient ausgegangen war. Rasseln über dem rechten unteren Lungenlappen; am 16. December begann von den lupösen Stellen aus ein Erysipel, welches mit Temperaturen bis $\mathbf{z u} 40,3^{\circ}$ in 14 Tagen verlief unter gleichzeitiger diffuser Bronchitis.

Vom 1. Januar fieberlos; die letzten Lupusknoten sind bis auf eine verdächtige Stelle ausgeheilt am 17. Januar 1892. Patient wird entlassen nnd ist bis August 1892 die Heilung controlint worden.

Therese Ganeis, 21 Jahre alt. Seit dem 2. Lebensjabre Eiterung links. Flüsterzahlen $2 \mathrm{Cm}$. Hammerextraction 15. Februar 1992, Der Amboss wird dislocirt, und jedesmal beim Eingehen mit dem Ambosshaken und dem Versuch zu drehen, zuclet der Facialis. Es wird deshalb Abstand genommen, den Amboss zu extrahiren. Nach der Operation, am 26. Februar, hat sich eine ziemlich lateral liegende neue Membran gebildet, in deren Mitte ein rübkorngrosses Loch ist, reines Blasegeräusch. Am 5. März ist das Loch mit einer Borke verklebt, nach deren Abziehen etwas Eiter erscheint. Am 12. März reichlicher Eiter. Am 22. März ist in der lateralen Membran vorn oben noch ein Loch entstanden. Die Brâcke zwischen den beiden Perforationen wird durchtrennt und der Spalt auftamponirt; am 23. und 24. März werden die Ränder geätzt; am 4. April ist das Ohr trocken, reines Blasegeräusch, es besteht ein neugebildetes Trommelfell, von der lateralen Membran ist nichts mehr zu sehen; Flüsterzahlen 1 Meter.

Zum Schluss möge noch über einen Fall berichtet werden, welcher uns die Unzuverlässigkeit der Diagnose des otitischen Hirnabscesses recht nahe legt. Es bot sich ein Symptomeomplex, auf Grund dessen wir eine genaue localisirte Diagnose auf einen otitischen Schläfenlappenabscess stellen zu können glaubten, und trotzdem wurde unsere Diagnose durch das Operationsergebniss nicht bestätigt. Dieser Fall (Stelzer) ist zur Hälfte schon von Braun in diesem Archiv I) publicirt.

Im Februar 1889 wurde er trepanirt und zweimal mit einer grossen Pravaz'schen Spritze und dann mit einem sclimalen Skalpell in die Substanz des linken Kleinhirns eingegangen, ohne dass Eiter gefunden wurde. Und dabei bestand ein Complex von Erscheinangen, welche das angeblich typische Bild eines Abscesses im linken Kleinhirn construiren. Bei demselben Kranken wurde im Sommer 1891 ein zweites Mal mit negativem Erfolge

1) Bd. XXIX. S. 169. 
im linken Schläfenlappen Eiter gesucht, weil alle damals bestehenden Erscheinungen, mittleres Fieber mit remittirendem Typus, hochgradige Pulsverlangsamung, cireumseripte Percussionsempfindlichkeit iber der Schuppe des linken Os temporale daranf hinwiesen, dass es sich um einen Abscess in dieser Region handeln müsse. Nach dem Eingriff verloren sich die cerebralen Erscheinungen allmählich wieder, ein Umstand, der in solehen Fällen auf eine durch den Abfluss von Liquor cerebrospinalis bedingte Verminderung des intracraniellen Druckes zurückgeführt wird. Der Kranke wurde für Jahr und Tag wieder arbeitsfähig.

Dem Einwande, dass in diesem Falle ein Abscess wohl vorhanden, derselbe aber nicht aufgefunden wurde, kann wohl damit begegnet werden, dass bei beiden Trepanationen sowohl die Knochenöffnung weit genug angelegt, als auch tief und schonungslos genug in die Hirnsubstanz eingedrungen wurde, so dass eine Eiteransammlung in der Tiefe, wenn eine solche vorhanden gewesen wäre, hätte aufgefunden werden müssen. 
Bericht über d. Thătigkeit d. Kgl. Tniversităts-Ohrenklinik zu Halle a. S.

\begin{tabular}{|c|c|c|c|c|c|c|c|}
\hline 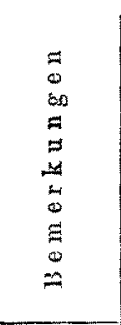 & 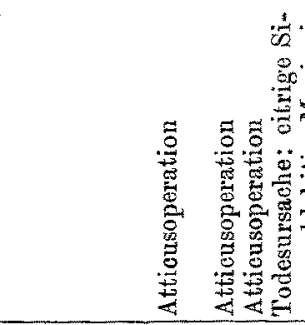 & & 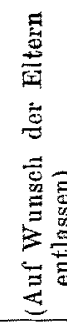 & & 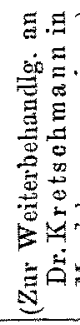 & & \\
\hline 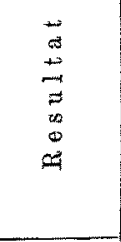 & 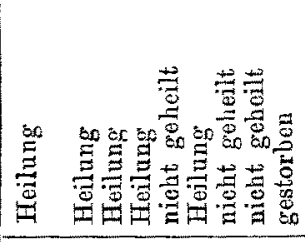 & 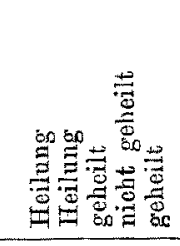 & 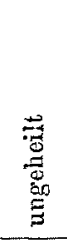 & 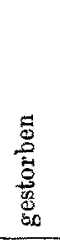 & 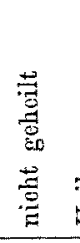 & 窇 & 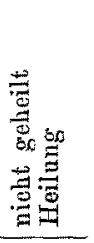 \\
\hline \multirow{2}{*}{ 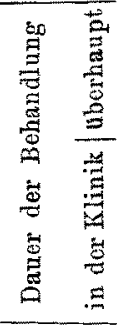 } & 1110 & 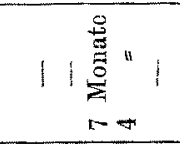 & 1 & 1 & 1 & 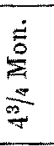 & 11 \\
\hline & 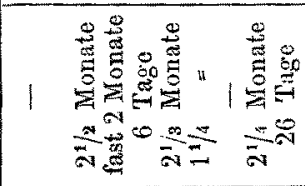 & 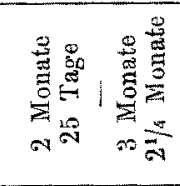 & 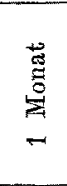 & 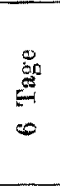 & 㞼 & 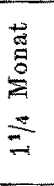 & | \\
\hline $\begin{array}{l}0 \\
\Xi \\
5 \\
5 \\
D \\
0 \\
0 \\
0 \\
0 \\
0 \\
0 \\
0 \\
0 \\
0 \\
0 \\
0 \\
50 \\
5 \\
0 \\
0\end{array}$ & 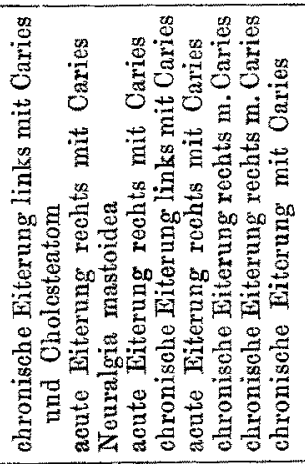 & 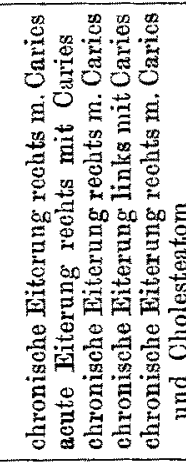 & 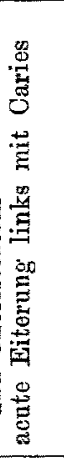 & \multicolumn{2}{|c|}{ 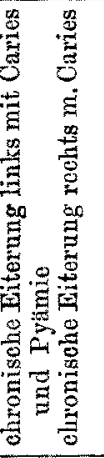 } & \multicolumn{2}{|c|}{ 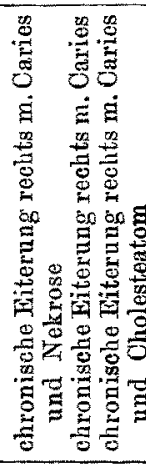 } \\
\hline 密回弯 & 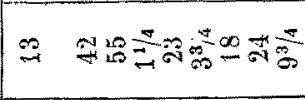 & 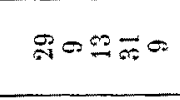 & $\sum_{\Gamma}^{0}$ & $\fallingdotseq$ & จำ & $?$ & F冷 \\
\hline $\begin{array}{l}\stackrel{0}{a} \\
\underset{z}{z} \\
\ddot{z}\end{array}$ & 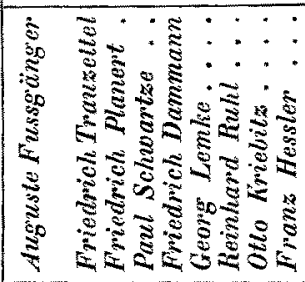 & 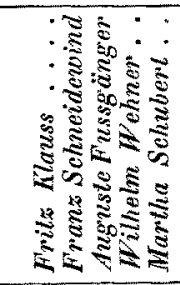 & 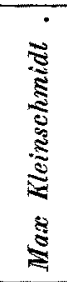 & 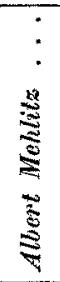 & 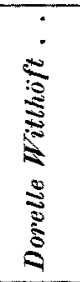 & 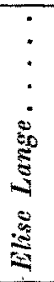 & 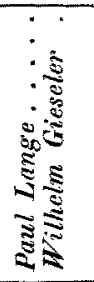 \\
\hline 点 & 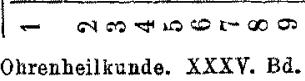 & 97 & $\stackrel{20}{\sim}$ & $\cong$ & & & 윰요 \\
\hline
\end{tabular}




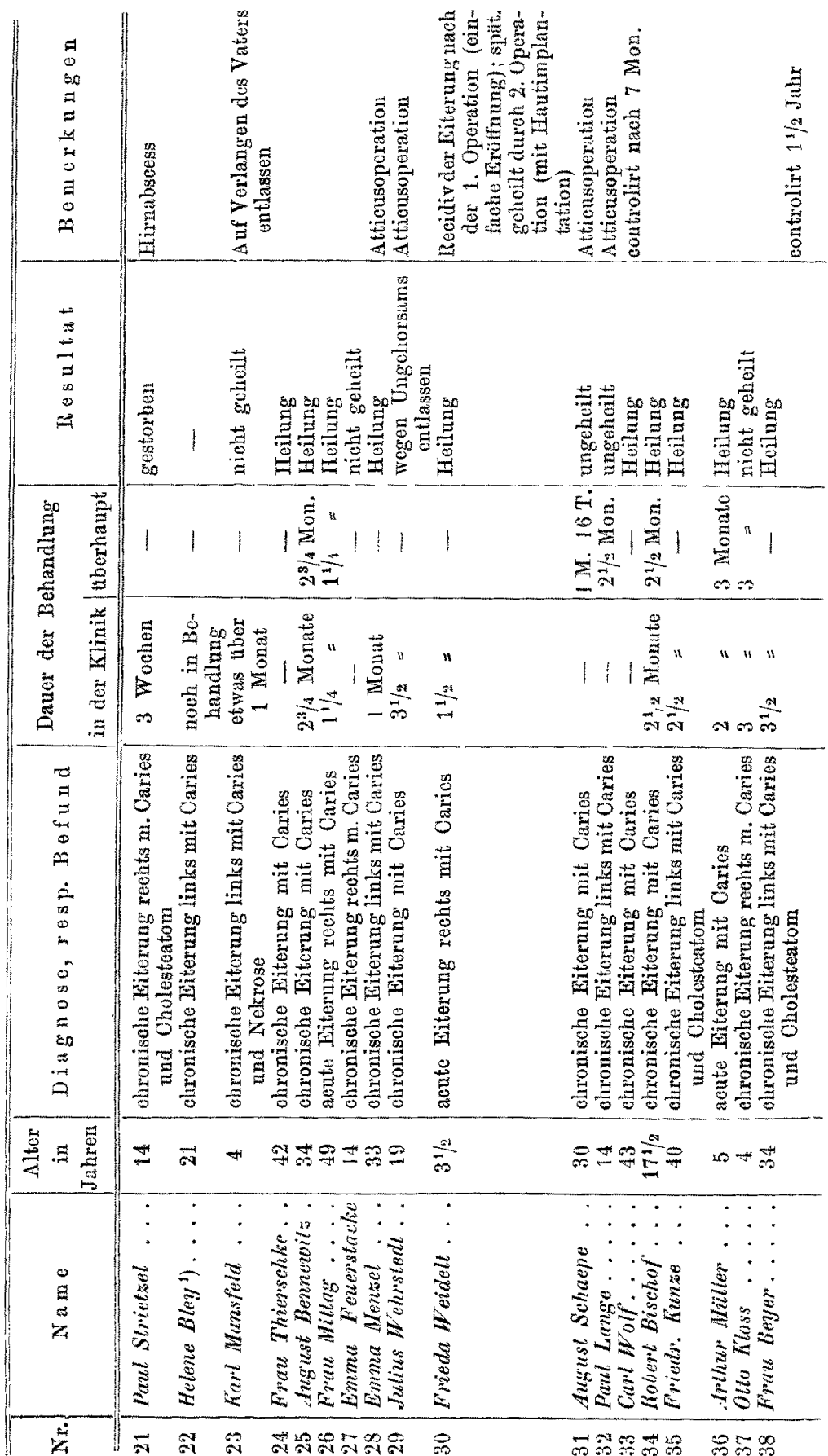


Bericht über d. Thătigkeit d. Kgl. Universitäts-Ohrenklinik zu Halle a. S.
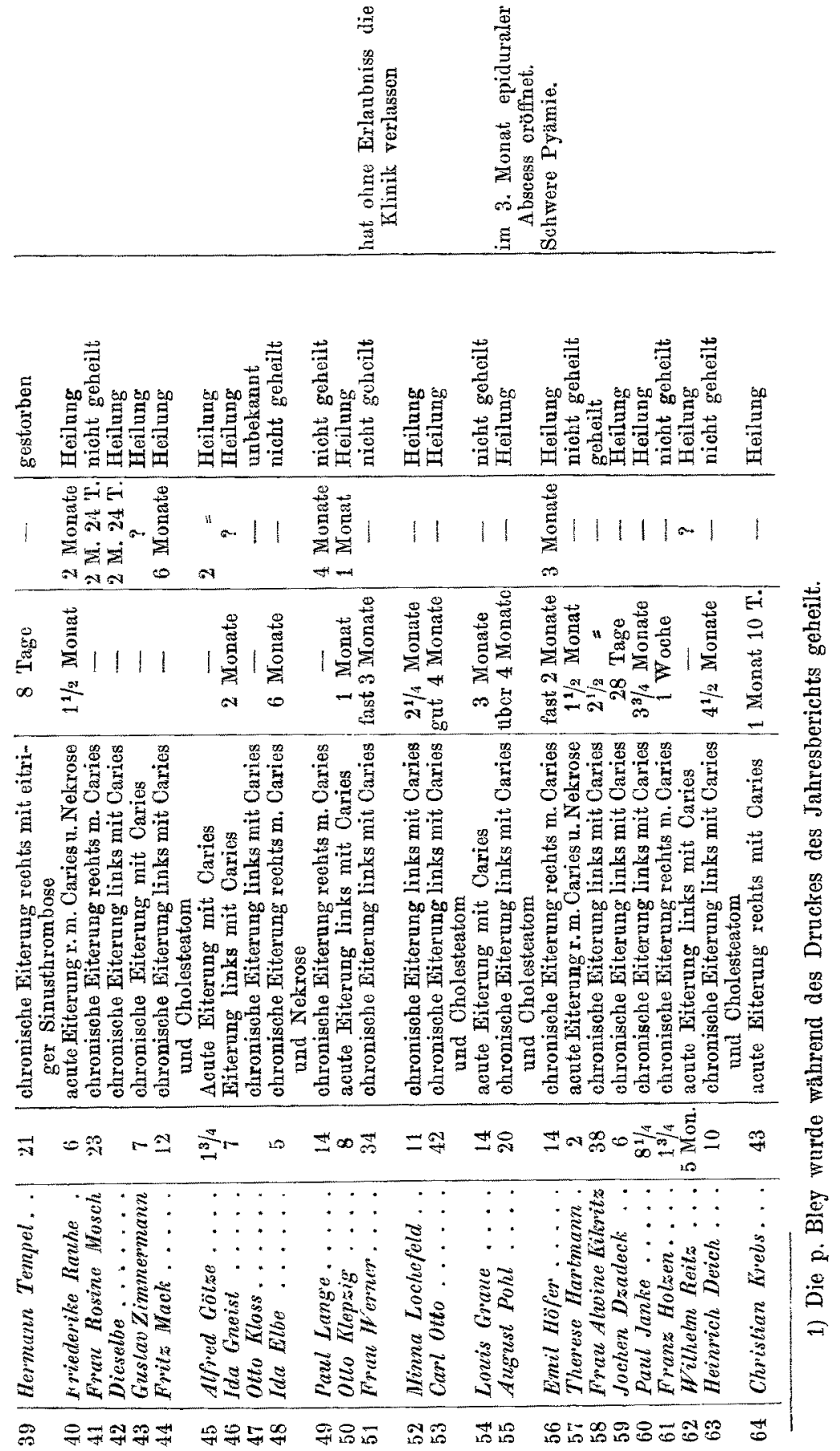


\begin{tabular}{|c|c|c|c|c|c|c|c|}
\hline 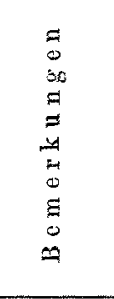 & 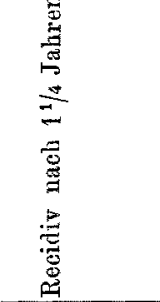 & & 急 & & & & \\
\hline 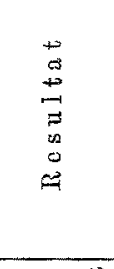 & 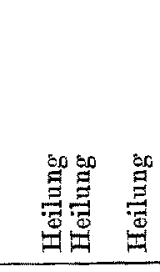 & 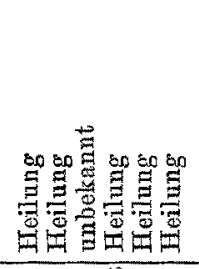 & 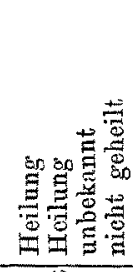 & 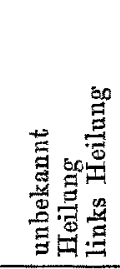 & 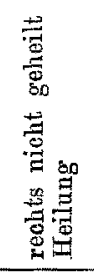 & 总। & 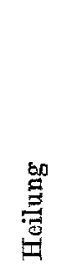 \\
\hline 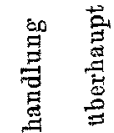 & $\sum_{-\infty}^{+}$ & 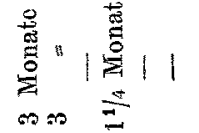 & 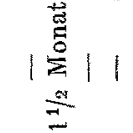 & 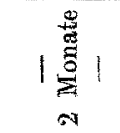 & 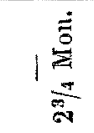 & $\sum_{-1}^{+}$ & 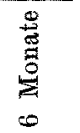 \\
\hline 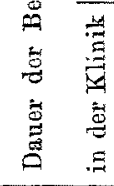 & | & 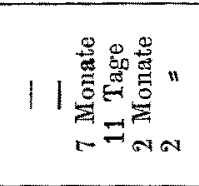 & 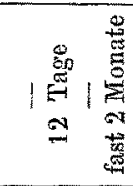 & 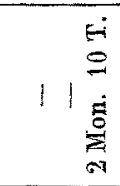 & 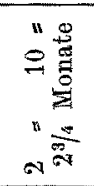 & 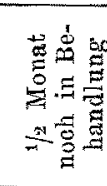 & $\frac{0}{30}$ \\
\hline 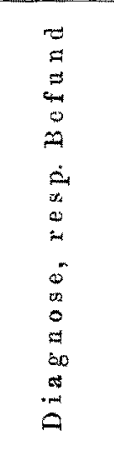 & 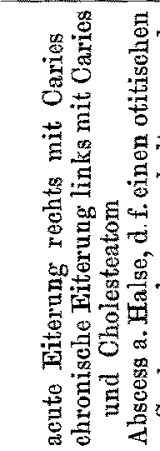 & 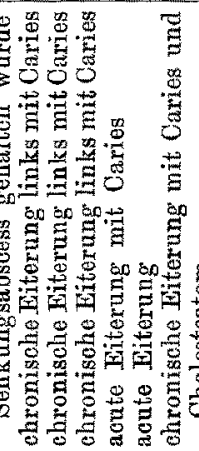 & 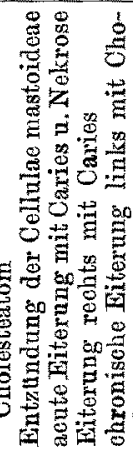 & 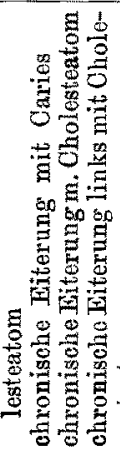 & 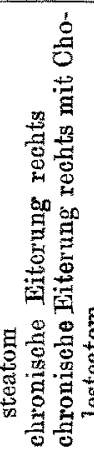 & 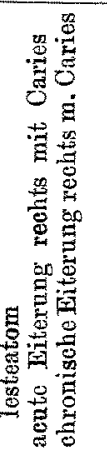 & 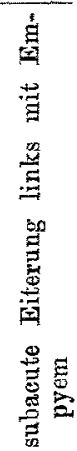 \\
\hline 总吅 & 言+ & |봃요 & $|\vec{N}| \stackrel{N}{2}$ & 11 웅 & 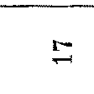 & 象里 & $\stackrel{\infty}{*}$ \\
\hline $\begin{array}{l}0 \\
\text { घ } \\
\text { 范 } \\
\end{array}$ & 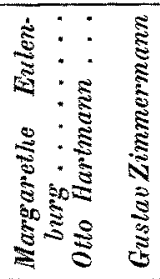 & 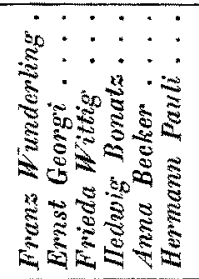 & 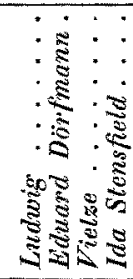 & 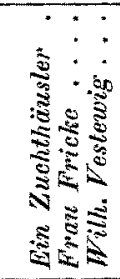 & 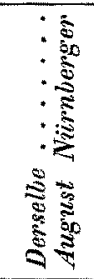 & 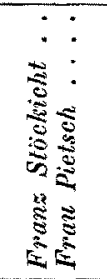 & 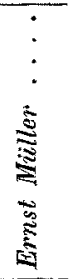 \\
\hline & & & & & & & \\
\hline
\end{tabular}

